Inspección médica

\title{
La incapacidad, indicador de salud laboral con alta variabilidad territorial
}

\section{Incapacity - Indicator of Occupational Health with High Territorial Variability}

José Manuel Vicente Pardo', Araceli López-Guillén García²

1. Instituto Nacional de la Seguridad Social Equipo Valoración Incapacidades. Gipuzkoa. España. Cátedra de Medicina Evaluadora y Pericial UCAM.

2. Instituto Nacional de la Seguridad Social. Murcia. España. Cátedra de Medicina Evaluadora y Pericial UCAM.

Recibido: 12-11-2019

Aceptado: 26-11-2019

\section{Correspondencia}

Araceli López-Guillén García.

Correo electrónico: araceli.lgg@gmail.com

José Manuel Vicente Pardo.

Correo electrónico: josemanuvicente@gmail.com

Resumen

Resumen: La incapacidad es un indicador de salud laboral, siendo exponente de su pérdida. La incapacidad laboral, tanto temporal como permanente, deriva de múltiples variables que la causan, la condicionan y la modulan, pero de entre todas ellas la significativa variabilidad de presentación por territorios (comunidades autónomas) plantea un mapa de salud laboral para su análisis causal.

Material y método: Se extrajeron los datos básicos sobre incapacidad temporal y permanente de la página de estadísticas de la seguridad social, procediéndose a su análisis y elaboración, comparando los datos de 2019 acumulados a septiembre, con los de estudio previo que efectuamos en 2017. Se revisaron hasta agosto 2019 así como datos del INE, Ministerio Sanidad, las siguientes bases de datos bibliográficas: SciELO, PUBMED, y se anotan fuentes concretas que se reseñan en bibliografía.

Objetivo: Constatar por territorios la diversidad presentación de incapacidad laboral, de la presentación del análisis de datos de incidencia, duración y prevalencia de la incapacidad temporal así como la diversa presentación de la incapacidad permanente y sus grados de incapacidad por ámbito geográfico autonómico. Y establecer las posibles causas de la misma. Dar valor a la incapacidad como indicador de salud laboral y plantear la diversidad de presentación, para la gestión integral e integradora de la prestación, y la mejora de la salud laboral con criterios no solo de protección económica sino preventiva laboral.

Conclusiones: La diferenciación territorial de la incapacidad laboral, está consolidada en el tiempo, como manifiesta el estudio que presentamos, pudiéndose afirmar que hay zonas más o menos saludables, según lo expresa el indicador de incapacidad laboral. Se puede afirmar que, en términos de salud laboral importa más el código postal que el código genético. Y más allá de otras consideraciones económicas y de

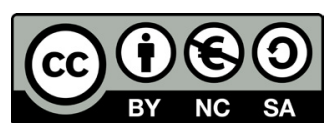

https://creativecommons.org/licenses/by-nc-sa/4.0/ 
gestión en cuanto al gasto, reflejan una diferente salud laboral por ámbito geográfico, desigualdades que es preciso abordar desde la perspectiva preventiva, ocupacional, sanitaria y social.

Med Segur Trab (Internet). 2019;65(257):261-284

Palabras clave: Incapacidad Laboral, Salud Laboral, Indicador de salud laboral.

Abstract

Abstract: Disability is an indicator of occupational health being at the same time an indicator of health' decline. The temporary and permanent labor incapacity derives from multiple variables causing, modulating and determining it. Among all of them, the significant variability of presentation by territories (autonomous communities) provides a map of occupational health for its causal analysis.

Material and Methods: The basic data of temporary and permanent disability were extracted from the social security data page. They were hereafter prepared to be analyzed and elaborated by comparing the data accumulated up to September 2019 with those compiled in the previous study of 2017. The following bibliographic databases SciELO and PUBMED as well as data from the National Statistical Institute, Ministry of Health, were reviewed up to August 2019. Specific sources are reviewed in the bibliography.

Objective: To verify by territory the diversity representation of the work incapacity, of the data analysis impact, of the duration and prevalence of temporary incapacity and the diverse representation of permanent incapacity together with its incapacity degrees by geographical areas (Autonomous Community) establishing its possible causes. To give value to the incapacity as an indicator of occupational health. To consider the diversity presentation for the integral and integrating benefit management and the improvement of occupational health, not only for economic protection criteria but also for occupational prevention.

Conclusions: As the present study indicates, the territorial differentiation of work disability become established over time, affirming that there are areas which are more or less healthy as the indicator of work incapacity shows; It can be therefore asserted, that in terms of occupational health the postal code seems to matter even more than the genetic code. Different occupational health rates are reflected in terms of spending across geographical areas beyond other economic and management considerations. Such inequalities need to be addressed from a preventive, occupational, health and social perspective.

Med Segur Trab (Internet). 2019;65(257):261-284

Keywords: Occupational Disability, Occupational Health, Occupational Health Indicator 


\section{ABREVIATURAS}

CCAA comunidades autónomas

INE Instituto Nacional de Estadística

INSS Instituto Nacional de la Seguridad Social

IP Incapacidad Permanente

IT Incapacidad Temporal

PIT Prórroga Incapacidad Temporal

\section{INTRODUCCIÓN}

Entendemos la incapacidad laboral como la situación del trabajador que como consecuencia de una enfermedad o un accidente está impedido para trabajar, bien de forma temporal o permanente.

La Ley General de Seguridad Social define en su artículo 169, las situaciones determinantes de incapacidad temporal, como las debidas a enfermedad común o profesional y a accidente, sea o no de trabajo, mientras el trabajador reciba asistencia sanitaria de la Seguridad Social y esté impedido para el trabajo, con una duración máxima de trescientos sesenta y cinco días, prorrogables por otros ciento ochenta días cuando se presuma que durante ellos puede el trabajador ser dado de alta médica por curación. Así mismo contempla los períodos de observación por enfermedad profesional.

La Ley General de Seguridad Social define en su artículo 193, la incapacidad permanente contributiva como la situación del trabajador que, después de haber estado sometido al tratamiento prescrito, presenta reducciones anatómicas o funcionales graves, susceptibles de determinación objetiva y previsiblemente definitivas, que disminuyan o anulen su capacidad laboral.

La incapacidad temporal es la situación temporal de pérdida de salud sobrevenida, impeditiva para el trabajo, a la espera de que el tratamiento oportuno logre la curación o la mejoría funcional suficiente para retornar al trabajo.

La incapacidad permanente es la situación de limitación funcional significativa y permanente de un proceso que incapacita para el desarrollo del trabajo.

Siendo tanto la una como la otra consideración de incapacidad laboral y por lo tanto de pérdida de la salud laboral.

La incapacidad laboral es el indicador de salud laboral, que mejor refleja su pérdida. La incapacidad laboral depende de múltiples variables, unas denominadas propias, porque son propias del trabajador y el trabajo, de causa inmediata y directa y otras denominadas impropias, pues son ajenas al trabajador y al trabajo, no son debidas al propio proceso del enfermar, ni a su tratamiento, ni a su evolución, ni a su repercusión limitante expresa para el trabajo, son por tanto indirectas, y pueden modular o expresar variaciones y manifestaciones del conjunto de datos.

La incapacidad laboral con carácter permanente manifiesta el indicador de retorno laboral y es muy útil de cara a valorar el impacto laboral de un proceso.

La imputación del trabajo en la causa del proceso, bien como accidente de trabajo (incluyendo las "enfermedades del trabajo" artículo 156. 2 e), bien como enfermedad profesional, es decir como "contingencia laboral", no excluye la valoración de la incapacidad laboral como indicador de salud laboral de la incapacidad como "contingencia común", pues es evidente que esta incapacidad laboral referencia de forma directa la salud laboral de los trabajadores al expresar su pérdida. La contingencia referencia la imputación de la prestación sanitaria y económica de un proceso y la competencia de su control y pago de la prestación, que en el supuesto de ser laboral compete a las mutuas, 
lo que no desvirtúa la consideración de la incapacidad laboral (no derivada de accidente de trabajo o enfermedad profesional) como un indicador de salud pública y por su acepción específica un indicador de salud laboral.

\section{La incapacidad como indicador de salud pública y salud laboral}

La incapacidad (el no retorno al trabajo permanente o la ausencia temporal) es un indicador de resultado sanitario (el regreso al trabajo tras incapacidad es una buena medida de los resultados de la atención sanitaria), es un indicador de gestión sanitaria (respecto a desviaciones derivadas de lista de espera o dificultades de acceso a pruebas diagnósticas o tratamientos), es un indicador de salud pública (nos mide el enfermar o el deterioro de la salud hasta el extremo de lo incapacitante), y en cuanto a la relación de la incapacidad con el trabajo es un claro indicador de salud laboral, por no referirnos a que es un claro indicador de calidad de vida (estar incapacitado es obvio que conlleva una mala calidad de vida, que afecta en lo personal y en el entorno inmediato del trabajador incapacitado).

La incapacidad laboral es un indicador de salud laboral de primer orden, es un indicador que referencia tanto las ausencias laborales por baja como el no retorno por incapacidad laboral permanente, más allá del habitual uso de la incapacidad como un indicador de "gasto". La incapacidad laboral debe de ser referenciada, más allá de las cuestiones económicas, como se acostumbra, como una cuestión de salud laboral ${ }^{1}$.

\section{VARIABLES EN LA INCAPACIDAD LABORAL}

De forma esquemática recogemos las diferentes variables de la incapacidad laboral. Agrupadas como variables propias e impropias.

Las denominadas propias, guardan relación con el trabajador y el trabajo, causan de forma inmediata y directa la incapacidad, y su prolongación e interfieren en el retorno y condicionan su carácter temporal o permanente. Destacando las variables salud/ enfermedad, lo sanitario y el trabajo, por formar parte de la propia definición de la situación de incapacidad laboral temporal o permanente. Confieren lo incapacitante de las limitaciones funcionales para el trabajo de forma determinante. Añadido a estas los factores psicosociales ${ }^{2}$ y, como no, el componente voluntario puede modular su aparición o prolongación y dificultar el retorno al trabajo.

Las denominadas impropias, son ajenas al trabajador y al trabajo, no son debidas al propio proceso del enfermar, ni a su tratamiento, ni a su evolución, ni a su repercusión limitante expresa para el trabajo, son por tanto indirectas, transversales y pueden modificar o expresar variaciones en la manifestación del conjunto de datos.

VARIABLES PROPIAS: Variables del trabajador y del trabajo

\section{Variabilidad salud/sanitaria}

- Salud/enfermedad: proceso individual

- Sistema sanitario: atención adecuada y temprana (en tiempo y forma)

\section{Variabilidad laboral}

- Ocupación, profesión, tareas.

- Sector de actividad, puesto de trabajo, riesgos laborales, condiciones de trabajo, circunstancias especiales, requerimientos específicos profesionales.

- Tipo de contrato, tamaño de la empresa, tipo de empresa

\section{Variabilidad individual}

- En el enfermar, la consecuencia incapacitante y la evolución del proceso.

— La "incapacidad refugio" de otras necesidades personales

— "Riesgo moral" componente voluntario en el acceso y prolongación 


\section{Variabilidad psicosocial}

- Aspectos personales

- Entorno familiar y social

- Entorno laboral y organizacional

- Riesgos psicosociales

VARIABLES IMPROPIAS: Variables ajenas al proceso de enfermar y el trabajo

\section{Variabilidad territorial}

- El código postal como incapacitante

- Distinta presentación de la IT por territorios

- Distinta presentación de la IP por territorios

\section{Variabilidad en la gestión}

- Prescriptores de IT

- Controladores de IT

- Sistema de protección

- Sistema de gestión

\section{Variabilidad normativa}

- Cambios en la norma, evolución

\section{Variabilidad económica}

- Crisis:

- La Incapacidad Temporal como fenómeno anticrisis

- La Incapacidad Permanente como recurso a las crisis

- Desempleo: la búsqueda de recursos

- Pago: cantidad percibida por incapacidad

Entendiendo que la incapacidad laboral descansa sobre las limitaciones funcionales para el trabajo, cabría pensar que las variables salud y laboral, fueran las más determinantes en la incapacidad, es decir, que la intensidad de las limitaciones derivadas de una enfermedad o lesión consolidan la repercusión en lo incapacitante laboral al ponerlo en relación con las requisitorias funcionales exigidas para el desarrollo de un trabajo; junto al factor edad y resto de factores psicosociales. Y la variable sanitaria o de disponibilidad y calidad de recursos sanitarios que puede condicionar la incapacidad, mediando en su tratamiento.

Así que la incapacidad laboral debiera responder a la variable salud/enfermedad y el trabajo.

Del resto de las variables, impropias o ajenas al a la enfermedad y el trabajo, es decir no concernientes al trabajador y su trabajo, la diversidad territorial es la manifestación conjunta de una diversidad según ámbito geográfico evidente, que no se explicaría de forma lógica, ni con variación sustancial, aludiendo al resto de estas variables impropias.

Del resultado de este estudio se evidencia que la incapacidad laboral tanto temporal como permanente derivada de múltiples variables que la causan la condicionan y la modulan, sobre todas ellas destaca la significativa variabilidad de presentación por territorios (comunidades autónomas), que plantea un mapa de salud laboral muy diferente. Esta diferenciación territorial de la incapacidad laboral, está además consolidada en el tiempo.

\section{La variabilidad de la incapacidad laboral puede referir:}

- La salud anómala

- Lo sanitario anómalo

- Trabajos anómalos

- Lo preventivo anómalo 
— Lo social anómalo

- Lo económico anómalo

- Gestión anómala

- La calificación anómala

- Comportamiento anómalo

Pero de todas estas variables, no todas tienen el mismo peso, ni el mismo efecto sobre los datos de incapacidad laboral. La salud/enfermedad, lo sanitario, lo preventivo y lo laboral centran las variables a las que tenemos que atender para una gestión adecuada.

La incapacidad laboral es un indicador de salud pública, un indicador de salud laboral, además de un indicador sanitario, como indicador sanitario de resultado.

\section{VARIABILIDAD TERRITORIAL DE LA INCAPACIDAD LABORAL}

- El código postal como incapacitante

- Distinta presentación de la IT por territorios

- Distinta presentación de la IP por territorios

Marc Lalonde en 1974, entonces ministro canadiense de Salud, defendió que la salud o la enfermedad no estaban relacionadas simplemente con factores biológicos o agentes infecciosos, sino que la mayoría de las enfermedades tenían una base u origen marcadamente socio-económica. Según el informe Lalonde, la salud está ligada a cuatro factores: lo biológico, los estilos de vida, el medio ambiente y los servicios sanitarios. Pero según este informe el de menor impacto es el a priori más considerado «lo sanitario". Otras referencias abogan por considerar esta misma acepción que más importa para la pérdida de salud el código postal que el código genético, entendiendo que tan importante en el enfermar no solo es lo biológico o lo saludable sanitario, sino los estilos de vida y más aún las condiciones de vida, en lo que podemos considerar el entorno inmediato socio económico del paciente, y que se denominan determinantes sociales.

Determinantes sociales entre los que destacan la situación laboral, el tipo de trabajo, la calidad en el trabajo, y la motivación laboral, y que pueden marcar las diferencias de salud según distintos ámbitos geográficos.

Los datos que a continuación iremos refiriendo sobre IT e IP y la distinta distribución territorial nos llevarían a pensar que hay territorios (comunidades autónomas) más o menos saludables, en lo que respecta a la incapacidad laboral o salud laboral. Partiendo de los básicos de la página de la seguridad social se han analizado los datos, elaborando de forma propia las tablas y cuadros de presentación. Así mismo hemos comparado algunos datos de IT de 2013,2017 y 2019; y en la IP datos de 2017 y 2019.

\section{3.a. Variabilidad de la Incapacidad Temporal (IT) por territorios}

Tendrán la consideración de situaciones determinantes de incapacidad temporal las debidas a enfermedad común o profesional y a accidente, sea o no de trabajo, mientras el trabajador reciba asistencia sanitaria de la Seguridad Social y esté impedido para el trabajo, con una duración máxima de trescientos sesenta y cinco días, prorrogables por otros ciento ochenta días cuando se presuma que durante ellos puede el trabajador ser dado de alta médica por curación.

\section{Duración de la IT}

Duración media: hace referencia a la duración, en dias, de los procesos de los que se ha registrado el alta. Se calcula dividiendo el número total de días de baja de los procesos cuya alta es conocida y se haya producido en el año, entre el número total de dichos procesos. 
Datos acumulados a 1 septiembre 2019, procesos de IT excepto autónomos. En cuanto a la duración media de las bajas esta es diferente por comunidades autónomas, sólo 6 comunidades están por debajo de la media nacional de 37,73, Aragón $(37,63)$, Baleares (34,3), Rioja (33,76), Madrid (31,83), Cataluña $(27,30)$ y Navarra $(25,6)$.

Las 6 CCAA con mayor duración son Murcia $(47,61)$, Ceuta $(47,79)$, Castilla y León $(48,11)$, C. Valenciana $(48,81)$, Asturias $(54,19)$, Galicia $(60,81)$ y Extremadura $(68,98)$. (Figura 1)

Figura 1. Duración media de los procesos

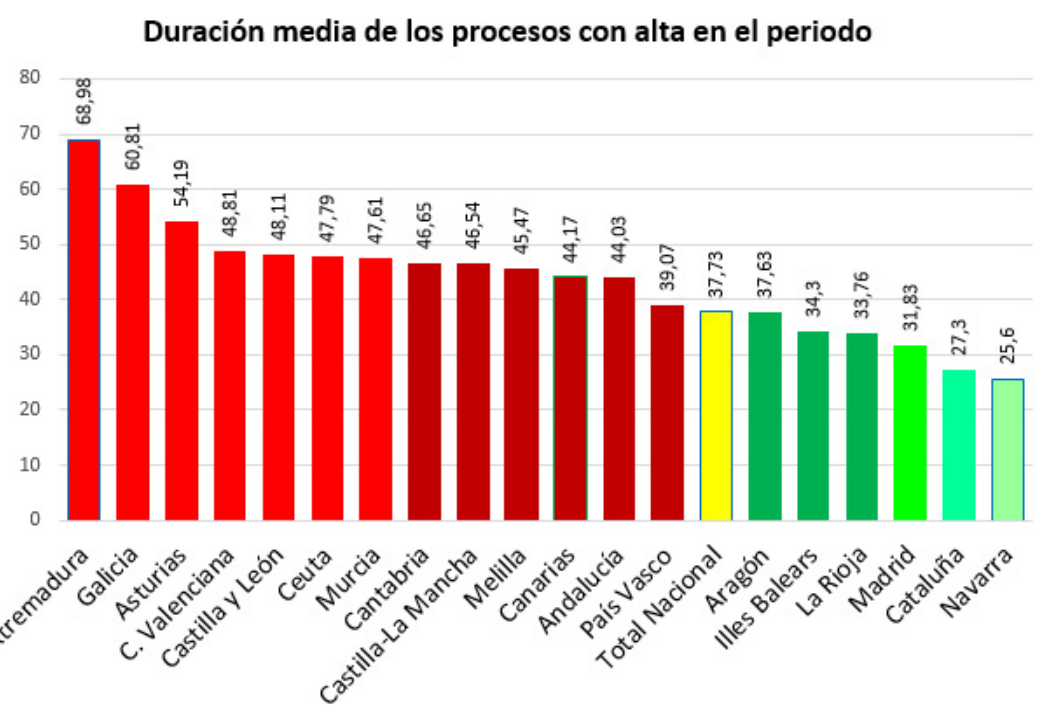

Duración media de los procesos con alta en el periodo, años 2013, 2017 y 2019 (acumulado agosto).

Tabla 1. Comparativa de duración de IT 2013, 2017 y 2019 (acumulado a agosto).

\begin{tabular}{llllll}
\hline \multicolumn{1}{c}{$\begin{array}{c}\text { Ámbito geográfico } \\
\mathbf{2 0 1 3}\end{array}$} & $\begin{array}{c}\text { Duración } \\
\text { media }\end{array}$ & $\begin{array}{c}\text { Ámbito geográfico } \\
\mathbf{2 0 1 7}\end{array}$ & $\begin{array}{c}\text { Duración } \\
\text { media }\end{array}$ & $\begin{array}{c}\text { Ámbito geográfico } \\
\text { 2019 }\end{array}$ & $\begin{array}{c}\text { Duración } \\
\text { media }\end{array}$ \\
\hline Extremadura & 57,62 & Extremadura & 65,73 & Extremadura & 68,98 \\
\hline Galicia & 57,44 & Galicia & 64,62 & Galicia & 60,81 \\
\hline C. Valenciana & 48,83 & Asturias & 56,82 & Asturias & 54,19 \\
\hline Asturias & 47,03 & Ceuta & 53,55 & C. Valenciana & 48,81 \\
\hline Murcia & 46,32 & C. Valenciana & 51,69 & Castilla y León & 48,11 \\
\hline Castilla-La Mancha & 45,12 & Murcia & 50,38 & Ceuta & 47,79 \\
\hline Castilla y León & 43,95 & Cantabria & 49,91 & Murcia & 47,61 \\
\hline Cantabria & 42,23 & Castilla y León & 49,40 & Cantabria & 46,65 \\
\hline Andalucía & 40,66 & Canarias & 47,63 & Castilla-La Mancha & 46,54 \\
\hline Ceuta & 35,07 & Castilla-La Mancha & 45,93 & Melilla & 45,47 \\
\hline País Vasco & 34,77 & Andalucía & 45,46 & Canarias & 44,17 \\
\hline Canarias & 34,01 & Melilla & 44,02 & Andalucía & 44,03 \\
\hline La Rioja & 33,88 & País Vasco & 38,03 & País Vasco & 39,07 \\
\hline Aragón & 33,36 & Aragón & 37,50 & Aragón & 37,63 \\
\hline Illes Balears & 31,48 & La Rioja & 34,97 & Illes Balears & 34,30 \\
\hline Melilla & 30,86 & Illes Balears & 34,18 & La Rioja & 33,76 \\
\hline Madrid & 29,44 & Madrid & 33,72 & Madrid & 31,83 \\
\hline Cataluña & 28,86 & Cataluña & 29,26 & Cataluña & 27,30 \\
\hline Navarra & 24,25 & Navarra & 26,09 & Navarra & 25,60 \\
\hline Total Nacional & $\mathbf{3 6 , 0 6}$ & Total Nacional & $\mathbf{3 9 , 5 1}$ & Total Nacional & $\mathbf{3 7 , 7 3}$ \\
\hline & & & & \\
\hline
\end{tabular}


De entre las 6 CCAA con mayor duración de la IT en las series comparadas Extremadura, Galicia, Asturias y la Comunidad Valenciana están presentes en las tres, igualmente entre las 6 CCAA con menor duración en las tres series están Navarra, Cataluña, Madrid, y Baleares.

Datos acumulados a 1 septiembre 2019, procesos de IT autónomos.

Figura 2. Duración media de los procesos en autónomos

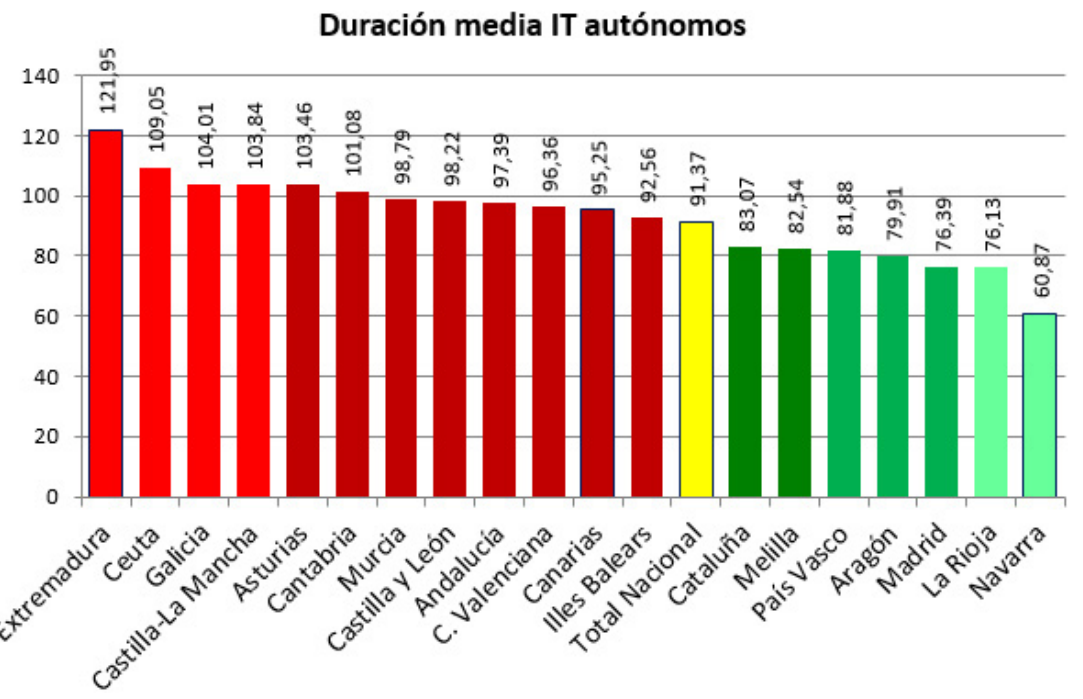

7 comunidades están por debajo de la media nacional de 91,37, Cataluña $(83,07)$, Melilla (82,54), País Vasco (81,88), Aragón (79,91), Madrid (76,39), Rioja (76,13), y Navarra (60,87). Las 7 CCAA con mayor duración son Extremadura $(121,95)$, Ceuta (109,05), Galicia (104,01), Castilla La Mancha (103,84), Asturias (103,46), Cantabria $(101,08)$, y Murcia $(98,79)$.

\section{¿A qué puede deberse el que tanto en autónomos como en régimen general algu- nas comunidades autónomas destaquen sobre el resto?}

Como vemos en duración por encima de la media coinciden Extremadura, Galicia y Asturias, y con menos duración Navarra, Rioja y Madrid.

\section{A qué podemos achacar la mayor duración de la IT}

La mayor duración de las bajas esconde deficiencias en la salud pública de la población por territorios y/o un deficiente sistema sanitario que no reporta atención sanitaria con la diligencia y efectividad que se requiere, incluso reflejar diferencias territoriales de acceso a los tratamientos o pruebas.

El propio Instituto Nacional de la Seguridad Social reconoció en 2014 que el 12,61 por ciento de las bajas por contingencia se prolongaba por estar el trabajador incluido en una lista de espera médica para pruebas, cirugía o rehabilitación, y esto no ha mejorado.

Los programas de intervención temprana en trastornos musculoesqueléticos o en cuadros de ansiedad depresión está demostrado son útiles, así como la dilación en la acción sanitaria están en la causa de su prolongación ${ }^{1,5}$.

De las otras variables "propias" como el tipo de actividad laboral, tanto el sector de actividad, como las ocupaciones desempeñadas serían destacables en cuanto a la duración, pues obviamente la duración de la IT depende directamente del tipo de trabajo para el que se está incapacitado. 
Figura 3. Listas de espera y duración de las bajas

Listas de espera y duración de las bajas laborales

Evolución de la lista de espera quirúrgica del SNS. 2009-2018

\begin{tabular}{|c|c|c|c|c|c|c|c|c|}
\hline CONCEPTO & $\begin{array}{r}\text { DIC. } \\
2009\end{array}$ & $\begin{array}{r}\text { JUNIO } \\
2015 \\
\end{array}$ & $\begin{array}{l}\text { DiC. } \\
2015\end{array}$ & $\begin{array}{l}\text { JUN1O } \\
2016^{*}\end{array}$ & $\begin{array}{l}\text { DIC. } \\
2016\end{array}$ & $\begin{array}{r}\text { JUN1O } \\
2017 \\
\end{array}$ & $\begin{array}{l}\text { DIC. } \\
2017\end{array}$ & $\begin{aligned} \text { JUN1O } \\
2018\end{aligned}$ \\
\hline Número de pacientes & 370.000 & 522.180 & 549.424 & 569.097 & 614.101 & 604.103 & 592.175 & 584.018 \\
\hline Tiempo medio de espera (dias) & 67 & 81 & 89 & 83 & 115 & 104 & 106 & 93 \\
\hline $\begin{array}{l}\text { Porcentaje de pacientes con } \\
>6 \text { meses de espera }\end{array}$ & 5,6 & 7,7 & 10,6 & 8,8 & 18,9 & 14,3 & 17 & 12,2 \\
\hline
\end{tabular}

Duración media de las IT en contingencia común entre 2009 y 2018

\begin{tabular}{|c|c|c|c|}
\hline DURACIÓN DE L & 2009 & 2018 & VAR. 2009 A 2018 (\%) \\
\hline 1 a 3 dias & 1,92 & 1,93 & 0,65 \\
\hline 4 a 15 dias & 7,71 & 8,00 & 3,79 \\
\hline 16 a 30 dias & 22,32 & 23,52 & 5,37 \\
\hline 31 a 60 dias & 44,85 & 46,29 & 3,22 \\
\hline 61 a 90 dias & 77,48 & 79,38 & 2,46 \\
\hline$>90$ dias & 229,73 & 275,18 & 19,78 \\
\hline
\end{tabular}

El componente voluntario no podemos decir es diferente de forma territorial. Tampoco la mayor o menor complacencia en el control de las bajas. Son componentes del "absentismo" no de la incapacidad laboral temporal.

\section{Procesos de duración muy prolongada. 365 días}

Si hablamos de duración conviene reseñar qué procesos son los que más duran, y la referencia que disponemos es el control de la IT a los 12 meses.

Figura 4. 20 diagnósticos principales en alcanzar los 365 días de baja. Datos INSS

\section{$20 \mathrm{dx}$ principales en alcanzar los 365 días}

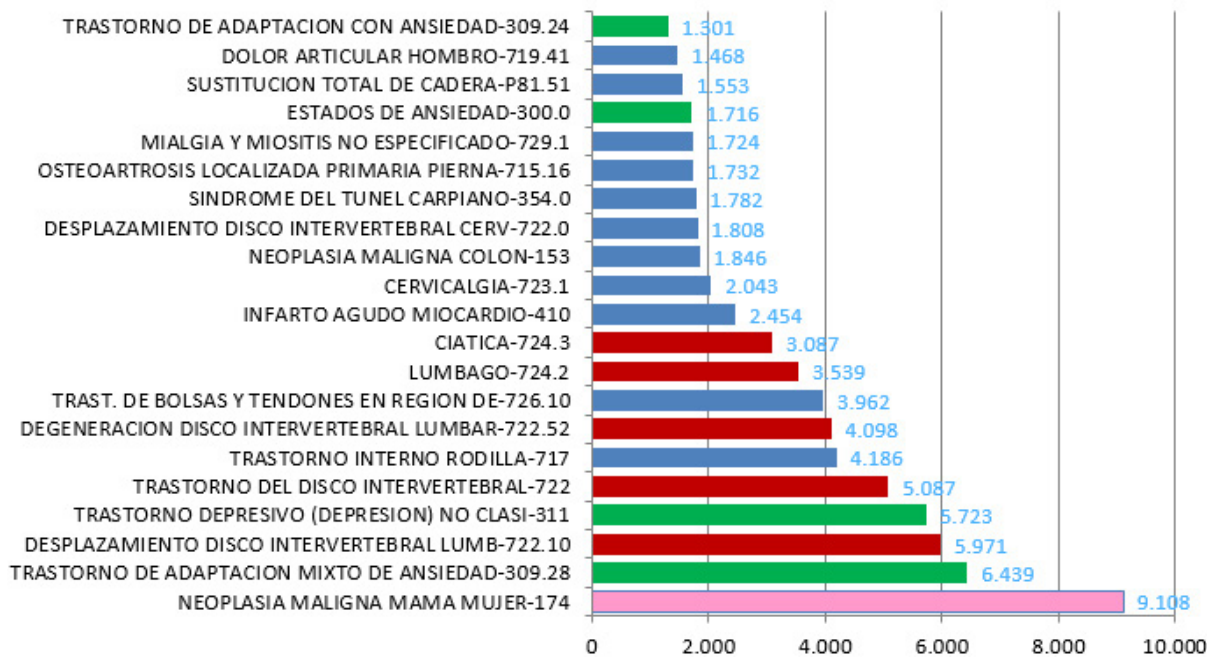

En morado el cáncer de mama "la neoplasia maligna de mama" que a lo largo de estos años destaca siempre como diagnóstico primero, pero en rojo tendríamos las "lumbalgias" y en verde los trastornos "psiquiátricos menores" que sumados confirman a ambos como diagnósticos principales en las bajas muy largas.

Tres grandes diagnósticos copan por tanto los 20 principales procesos en alcanzar los 365 días: las lumbalgias, los trastornos psiquiátricos menores y el cáncer de mama. Los 20 primeros diagnósticos recogidos en la Figura 3 suponen 70.627 casos, es decir, el 30\% de todos los procesos que llegan a 365 días de IT. 
En 2018 se iniciaron 5.843 .809 procesos de IT, 227.536 procesos de Incapacidad Temporal (IT) llegaron a los 365 días de duración, y en ese momento el 27,90\% (63.486) se resolvieron con declaración de Incapacidad Permanente (IP), el 31,42\% (71.512) con Alta Médica, y el 40,66\% (92.538) con consideración de Prórroga de IT.

El 3,89\% de los procesos iniciales de IT alcanzan los 365 días, un 1,58\% sobrepasarán los 365 días.

También conviene conocer que el $\mathbf{6 0} \%$ de los procesos de IT tiene una duración menor de 15 días. E1 $72 \%$ de las bajas se resuelven entre 1 y 30 días, y el $84 \%$ entre 1 día y 60 días. E1 11,5\% se resolverán entre 61 y 180 días. Las bajas de más de 90 días, suponen $69 \%$ del total de días perdidos por los trabajadores asalariados.

En este estudio no vamos a hablar de costes de la IT, pero citemos que el $\mathbf{8 0 \%}$ del gasto se concentrará en procesos de IT de más de 90 días.

Por otra parte reseñar que los procesos de baja de muy larga duración tienen un riesgo alto de convertirse en incapacidad permanente, en torno al 35\%; tienen un alto "riesgo moral", componente voluntario de prolongación de la situación, téngase en cuenta que la cronicidad de estas bajas crean una sensación al trabajador de que no va a existir curación, suponen una pérdida de habilidades competenciales en muchos casos, miedo al retorno por considerar al trabajo perjudicial; y tienen alto riesgo laboral pues tras el alta puede que el trabajador concluya en el despido, en la no contratación posterior, en el no reconocimiento de aptitud a pesar de la no declaración de la incapacidad permanente o en el alejamiento del trabajo por desistimiento personal ${ }^{3,4}$.

A continuación, exponemos (Tabla 2) datos por CCCA referentes a Esperanza de Vida (EV), años de Vida Saludable (EVS), años con Limitación de Actividad (LA) al nacer, Tasa Ajustada Mortalidad (TAM) 2015, Índice de Dependencia (ID) 2017, extraídos de la web del Ministerio de Sanidad.

Tabla 2. Esperanza de Vida (EV), Años de Vida Saludable (EVS), Años con Limitación de Actividad (LA) al nacer por comunidad autónoma, Tasa Ajustada Mortalidad (TAM) 2015 Índice de Dependencia (ID) 2017.

\begin{tabular}{lccccc}
\hline \multicolumn{1}{c}{ AMBITO GEOGRAFICO } & EV & EVS & LA & TAM & ID \\
\hline ANDALUCIA & 81,5 & 65,4 & 16,2 & 520,4 & 51,32 \\
\hline ARAGON & 83,0 & 72,5 & 10,5 & 454,5 & 57,59 \\
\hline ASTURIAS & 82,3 & 63,6 & 18,7 & 485,2 & 57,58 \\
\hline BALEARES & 82,6 & 65,9 & 16,8 & 470,4 & 46,52 \\
\hline CANARIAS & 82,3 & 58,2 & 24,1 & 486,8 & 43,70 \\
\hline CANTABRIA & 82,9 & 72,1 & 10,8 & 458,0 & 55,05 \\
\hline CASTILLA-LA MANCHA & 83,1 & 69,6 & 13,5 & 451,9 & 53,81 \\
\hline CASTILLA Y LEON & 83,8 & 69,9 & 13,9 & 458,0 & 60,09 \\
\hline CATALUÑA & 83,4 & 66,7 & 16,7 & 440,8 & 55,46 \\
\hline C. VALENCIANA & 82,5 & 66,6 & 15,9 & 478,2 & 54,31 \\
\hline EXTREMADURA & 82,2 & 67,6 & 14,6 & 487,8 & 53,96 \\
\hline GALICIA & 82,9 & 64,6 & 18,3 & 459,3 & 59,55 \\
\hline MADRID & 84,4 & 68,3 & 16,2 & 400,9 & 52,20 \\
\hline MURCIA & 82,4 & 65,6 & 16,8 & 479,3 & 51,86 \\
\hline NAVARRA & 84,0 & 70,6 & 13,3 & 413,5 & 56,81 \\
\hline PAIS VASCO & 83,6 & 67,3 & 16,4 & 437,5 & 59,14 \\
\hline LA RIOJA & 83,4 & 68,4 & 15,0 & 430,6 & 57,04 \\
\hline CEUTA & 80,5 & 62,4 & 18,1 & 525,0 & 50,95 \\
\hline MELILLA & 80,5 & 62,4 & 18,1 & 574,2 & 55,31 \\
\hline TOTAL NACIONAL & 82,8 & 66,7 & 16,1 & 462,1 & 53,83 \\
\hline
\end{tabular}


Así mismo referimos la valoración que la Federación de Asociaciones para la Defensa de la Sanidad Pública ha elaborado de "Los servicios sanitarios de las CCAA" cuya comparativa global por CCAA según diferentes parámetros sería la recogida a continuación. (Figura 4)

Figura 5. Comparativa de Servicios Sanitarios por CCAA

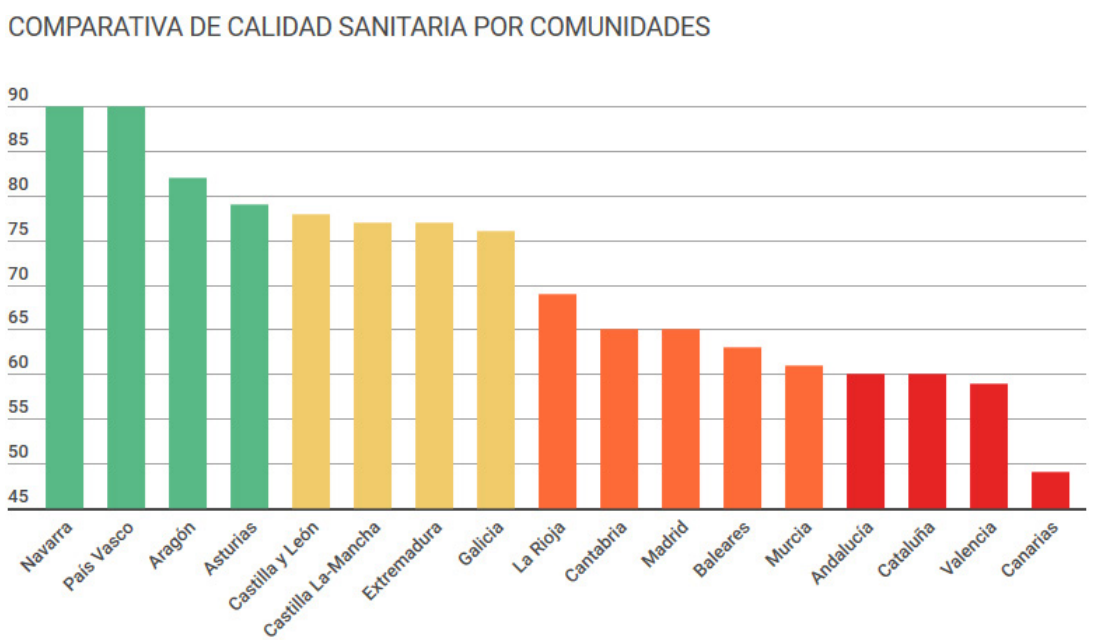

Para comparativas por comunidades autónomas de servicios prestados por las comunidades autónomas también recomendamos el análisis del informe: "La sanidad española en cifras 2018" de la Fundación Gaspar Casal. Que muestra los principales indicadores que describen el funcionamiento y resultados del Sistema Nacional de Salud público, comparando los datos de todas las autonomías que componen nuestro país y su evolución más reciente. ${ }^{7}$

\section{Incidencia IT}

En cuanto a la incidencia media mensual por cada mil trabajadores, de la IT (excepto autónomos), de forma significativa son algunas de las comunidades autónomas donde las bajas son más cortas las que tienen una mayor incidencia de las bajas por mil trabajadores. (Figura 6)

Figura 6. Incidencia media mensual de la IT por mil trabajadores excepto autónomos

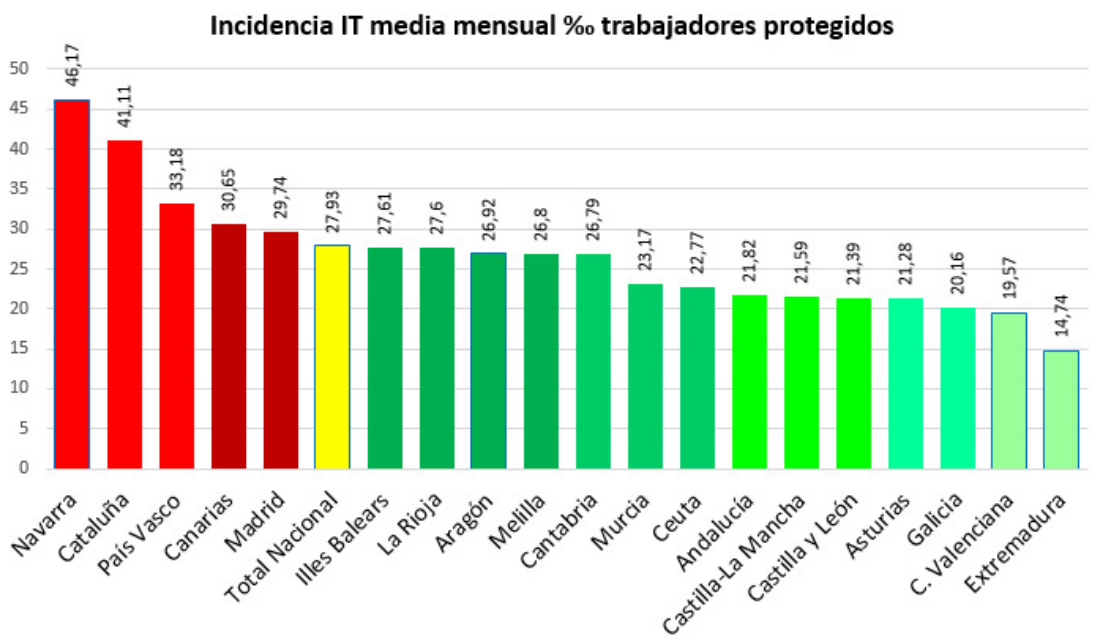

La incidencia de la IT por mil trabajadores, (Figura 6) refleja por encima de la media nacional de $27,93 \%$ a Navarra con $46,17 \%$, Cataluña con $41,11 \%$, País Vasco 31,18\%o, Canarias con 30,65\%, Madrid con 29,74\%o, y las de menor incidencia Asturias 
21,28\%o, Galicia 20,16\%o, C. Valenciana 19,57\% y Extremadura 14,74\%o; es decir aquellas CCAA, con mayor duración de las bajas, tienen menor incidencia.

Por otra parte si comparamos los datos de las series anuales 2013, 2017 y 2019 (Tabla 3), de entre las 6 CCAA con mayor incidencia de IT destacan y coinciden en las tres series Navarra, Cataluña, País Vasco, Madrid y Baleares y por este orden. Y Extremadura, C. Valenciana, Galicia y Castilla León coinciden en su aparición entre las 6 CCAA con menor incidencia de IT por mil trabajadores y por este orden.

Tabla 3. Incidencia media mensual \%o trabajadores protegidos años 2013, 2017, 2019 (acumulado agosto)

\begin{tabular}{|c|c|c|c|c|c|}
\hline $\begin{array}{l}\text { Ámbito geográfico } \\
2013\end{array}$ & $\begin{array}{c}\text { Incidencia } \\
\text { media }\end{array}$ & $\begin{array}{c}\text { Ámbito geográfico } \\
2017\end{array}$ & $\begin{array}{c}\text { Incidencia } \\
\text { media }\end{array}$ & $\begin{array}{c}\text { Ámbito geográfico } \\
2019\end{array}$ & $\begin{array}{c}\text { Incidencia } \\
\text { media }\end{array}$ \\
\hline Navarra & 31,31 & Navarra & 39,51 & Navarra & 46,17 \\
\hline Cataluña & 24,19 & Cataluña & 32,35 & Cataluña & 41,11 \\
\hline País Vasco & 22,89 & País Vasco & 28,49 & País Vasco & 33,18 \\
\hline Madrid & 19,96 & Aragón & 23,78 & Canarias & 30,65 \\
\hline Canarias & 19,88 & Illes Balears & 24,46 & Madrid & 29,74 \\
\hline Illes Balears & 19,43 & Madrid & 24,01 & Illes Balears & 27,61 \\
\hline Melilla & 19,26 & Canarias & 22,97 & La Rioja & 27,60 \\
\hline Aragón & 18,56 & La Rioja & 22,23 & Aragón & 26,92 \\
\hline Cantabria & 17,82 & Cantabria & 21,14 & Melilla & 26,80 \\
\hline La Rioja & 17,74 & Murcia & 19,55 & Cantabria & 26,79 \\
\hline Murcia & 16,22 & Melilla & 19,31 & Murcia & 23,17 \\
\hline Asturias & 15,61 & Castilla-La Mancha & 19,01 & Ceuta & 22,77 \\
\hline Ceuta & 15,48 & Ceuta & 18,37 & Andalucía & 21,82 \\
\hline Andalucía & 14,9 & Andalucía & 17,85 & Castilla-La Mancha & 21,59 \\
\hline Castilla y León & 14,06 & Asturias & 17,73 & Castilla y León & 21,39 \\
\hline Castilla-La Mancha & 13,87 & Castilla y León & 17,51 & Asturias & 21,28 \\
\hline Galicia & 13,78 & Galicia & 16,87 & Galicia & 20,16 \\
\hline C. Valenciana & 12,93 & C. Valenciana & 16,17 & C. Valenciana & 19,57 \\
\hline Extremadura & 10,13 & Extremadura & 12,16 & Extremadura & 14,74 \\
\hline Total Nacional & 18,19 & Total Nacional & 22,77 & Total Nacional & 27,93 \\
\hline
\end{tabular}

En cuanto a la incidencia media mensual de la IT por cada mil trabajadores, autónomos, la variabilidad territorial es significativa en los extremos es decir las CCAA con mayor y las de menor incidencia. (Figura 7).

La incidencia de la IT por mil trabajadores autónomos, (Figura 7) sitúan por encima de la media nacional de 9,55\%, a Navarra con 15,16\%o, Murcia con 12,08\%o, Aragón con 10,70\%o, Asturias con 10,7\%o, Cantabria 10,69\% y las de menor incidencia Canarias 8,75\%, C. Valenciana 8,67\%o, Ceuta con 8,41\%o, Madrid 8,11\%o, y Baleares $6,12 \%$.

\section{Qué procesos son los más frecuentes en causar bajas}

De entre los 21 primeros diagnósticos en causar IT en 2018 el diagnóstico más frecuente y destacado en las bajas iniciadas fue el lumbago, también es llamativo que el trastorno depresivo y el estado de ansiedad, aparezcan con significativo número de casos que sumados formarían el cuarto diagnóstico más frecuente de las bajas iniciales. 
Figura 7. Incidencia media mensual de la IT por mil trabajadores autónomos

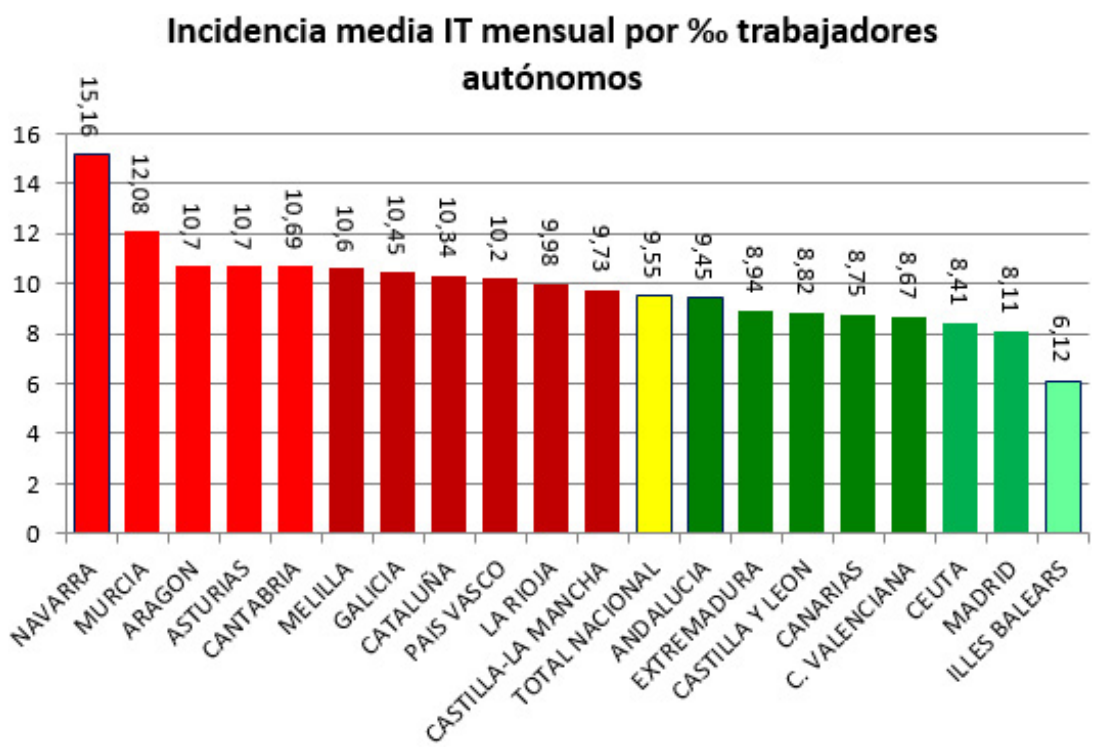

Figura 8. 21 diagnósticos más frecuentes en el inicio de IT en 2018. Datos INSS

21 Diagnósticos mas frecuentes en inicio de IT

( Total de procesos de IT 5.843.80)

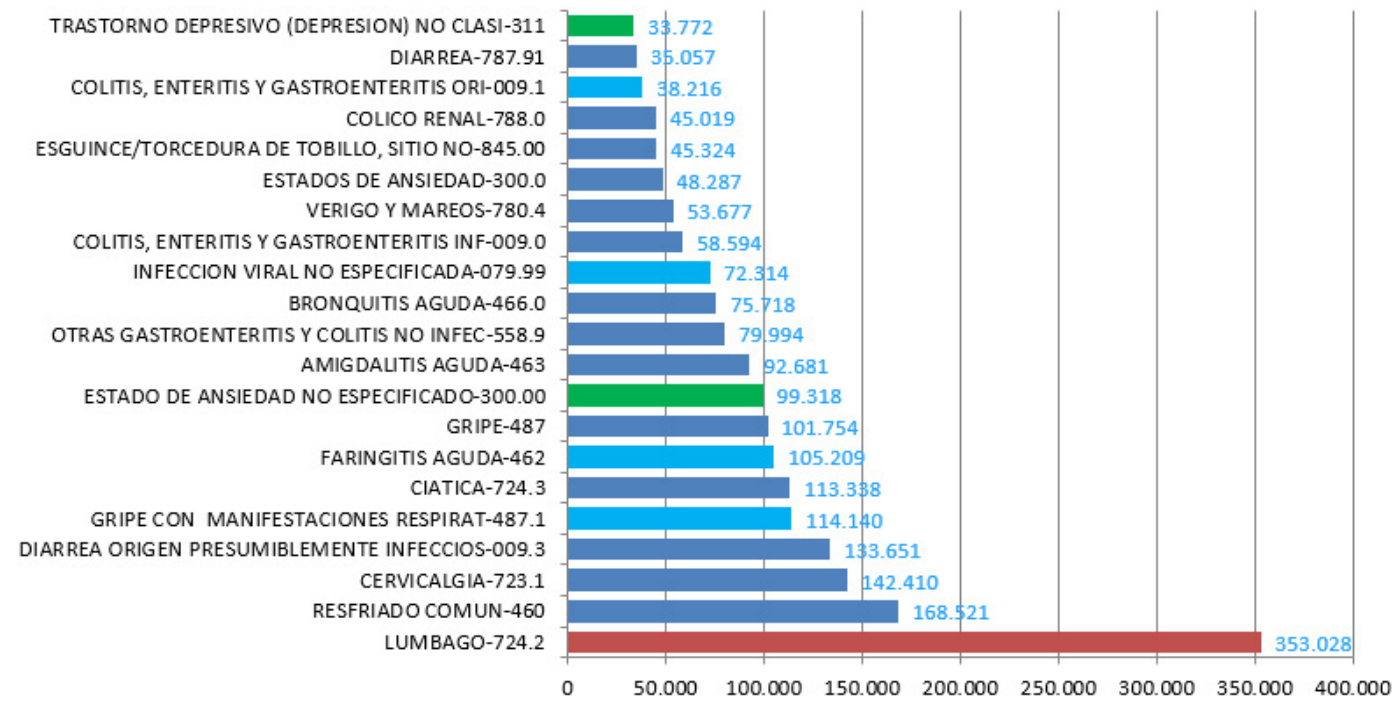

Más llamativo resulta cuando recogemos los 21 diagnósticos con más días consumidos de IT en 2018, porque las "lumbalgias" y la "ansiedad-depresión" son los procesos con más días consumidos.

Las lumbalgias consumieron 18.754 .388 días de IT el $\mathbf{9 , 0 4 \%}$ del total de los días de IT 2018, y la “ansiedad-depresión” 15.808.649 días de baja, el 7,62\%.

La mayor incidencia de la IT por territorios, pudiera explicarse por déficit de salud pública de la población, déficit preventivo del sistema sanitario, población laboral de mayor riesgo, o determinantes psicosociales.

Los procesos más frecuentes y los que mayores días consumen de baja las "lumbalgias" y las "ansiedades" son llamada de atención para la prevención en salud laboral, y para la adopción de medidas de atención temprana para procurar pronta recuperación. 
Figura 9. 21 diagnósticos que más días de IT consumieron en 2018. Datos INSS

(Total días de IT 207.252.343)

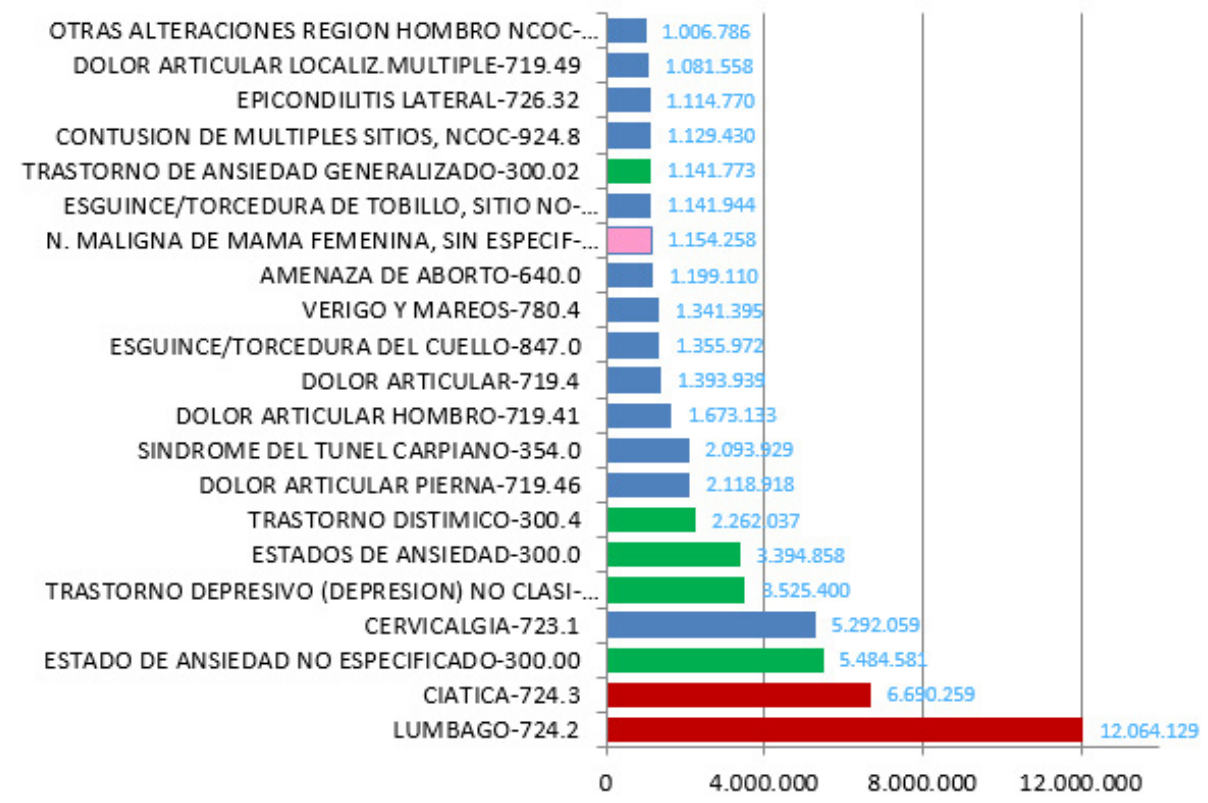

Otras hipótesis en la mayor incidencia de las bajas, como la mayor complacencia en el inicio de la IT o el componente voluntario del trabajador, no están demostradas y no deben ser por si mismas diferenciales territoriales y victimizan al trabajador y al sistema sanitario.

\section{Prevalencia IT}

En cuanto a la prevalencia, (Figura 10) es decir procesos de IT que continúan abiertos en el periodo por cada mil trabajadores Canarias (42,23), Galicia $(41,52)$, País Vasco $(38,58)$, Cantabria (38,49), Melilla (37,29), Murcia (36,92), Navarra (35,64), se sitúan de forma destacada como 7 CCAA con alta prevalencia, con un valor del Total Nacional de $(33,16)$ y en cuanto a las 6 CCAA menos prevalentes C. Valenciana (31,51), Castilla La Mancha (31,25), Aragón (31,09), Baleares $(30,76)$, Madrid $(27,84)$ y La Rioja $(26,74)$.

Figura 10. Prevalencia de la IT por mil trabajadores.

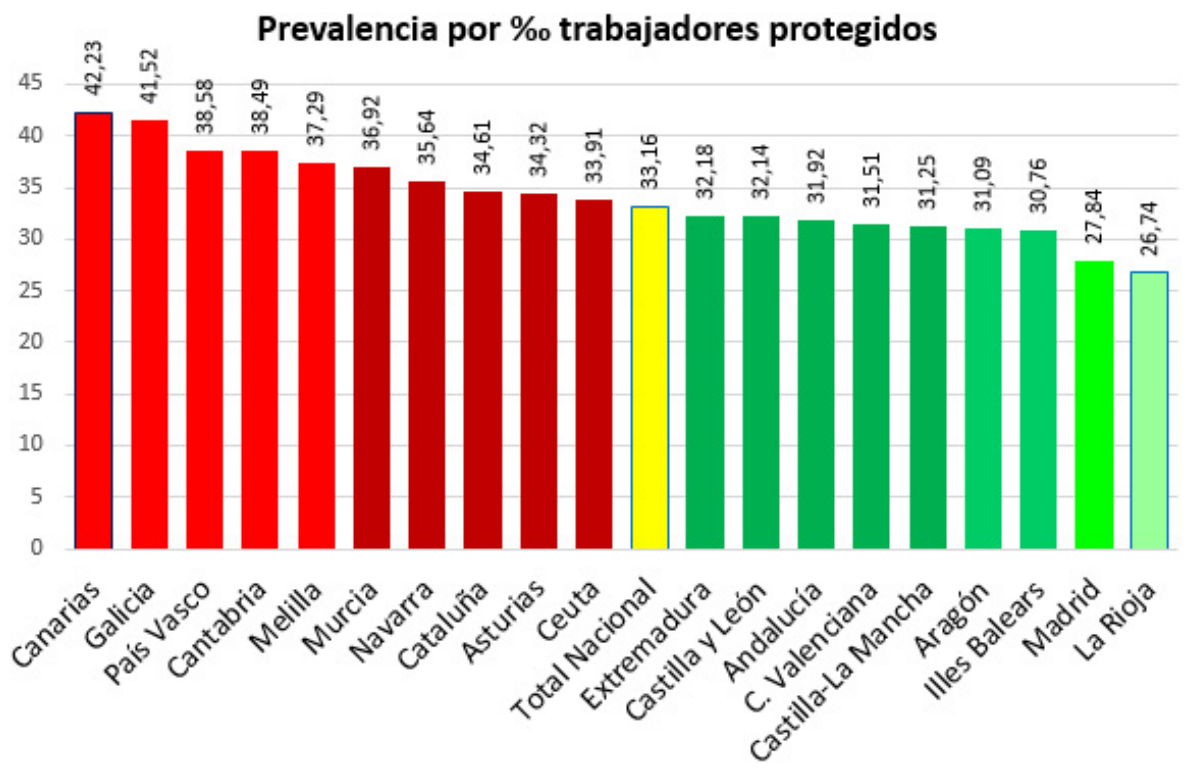


Tabla 4. Prevalencia \%o trabajadores protegidos años 2013, 2017, 2019 (acumulado agosto)

\begin{tabular}{|c|c|c|c|c|c|}
\hline $\begin{array}{c}\text { Ámbito } \\
\text { geográfico } \\
2013\end{array}$ & Prevalencia & $\begin{array}{c}\text { Ámbito } \\
\text { geográfico } \\
2017\end{array}$ & Prevalencia & $\begin{array}{c}\text { Ámbito } \\
\text { geográfico } \\
2019\end{array}$ & Prevalencia \\
\hline Cantabria & 26,47 & Canarias & 38,81 & Canarias & 42,23 \\
\hline Asturias & 25,93 & Cantabria & 38,09 & Galicia & 41,52 \\
\hline País Vasco & 25,60 & Asturias & 37,50 & País Vasco & 38,58 \\
\hline Galicia & 25,32 & País Vasco & 37,20 & Cantabria & 38,49 \\
\hline Murcia & 25,21 & Galicia & 36,75 & Melilla & 37,29 \\
\hline Navarra & 24,20 & Murcia & 34,23 & Murcia & 36,92 \\
\hline Canarias & 23,34 & Navarra & 33,47 & Navarra & 35,64 \\
\hline Ceuta & 22,46 & Cataluña & 32,56 & Cataluña & 34,61 \\
\hline Cataluña & 22,12 & Castilla-La Mancha & 31,22 & Asturias & 34,32 \\
\hline Aragón & 21,67 & Ceuta & 30,58 & Ceuta & 33,91 \\
\hline Baleares & 21,23 & Aragón & 30,53 & Castilla y León & 32,14 \\
\hline Castilla-La Mancha & 21,04 & Castilla y León & 29,89 & Extremadura & 32,18 \\
\hline C. Valenciana & 20,69 & Illes Balears & 29,47 & Andalucía & 31,92 \\
\hline Castilla y León & 20,41 & C. Valenciana & 29,22 & C. Valenciana & 31,51 \\
\hline Extremadura & 19,53 & Extremadura & 29,17 & Castilla-La Mancha & 31,25 \\
\hline Madrid & 18,91 & Madrid & 27,74 & Aragón & 31,09 \\
\hline Andalucía & 18,55 & Andalucía & 27,60 & Illes Balears & 30,76 \\
\hline Melilla & 18,45 & Melilla & 27,48 & Madrid & 27,84 \\
\hline La Rioja & 18,43 & La Rioja & 26,51 & La Rioja & 26,74 \\
\hline Total Nacional & 21,25 & Total Nacional & 31,10 & Total Nacional & 33,16 \\
\hline
\end{tabular}

Galicia, País Vasco, Cantabria y Murcia figuran en las tres series anuales como CCCA con alta prevalencia y La Rioja y Madrid se sitúan como las menos prevalentes.

En cuanto al volumen de los procesos el $\mathbf{5 7 , 8 0 \%}$ corresponden a 3 comunidades autónomas, Cataluña, Madrid y Andalucía. (Figura 11), en lógica traslación de ser las comunidades autónomas con mayor número de trabajadores.

Figura 11. Número medio mensual de procesos iniciados

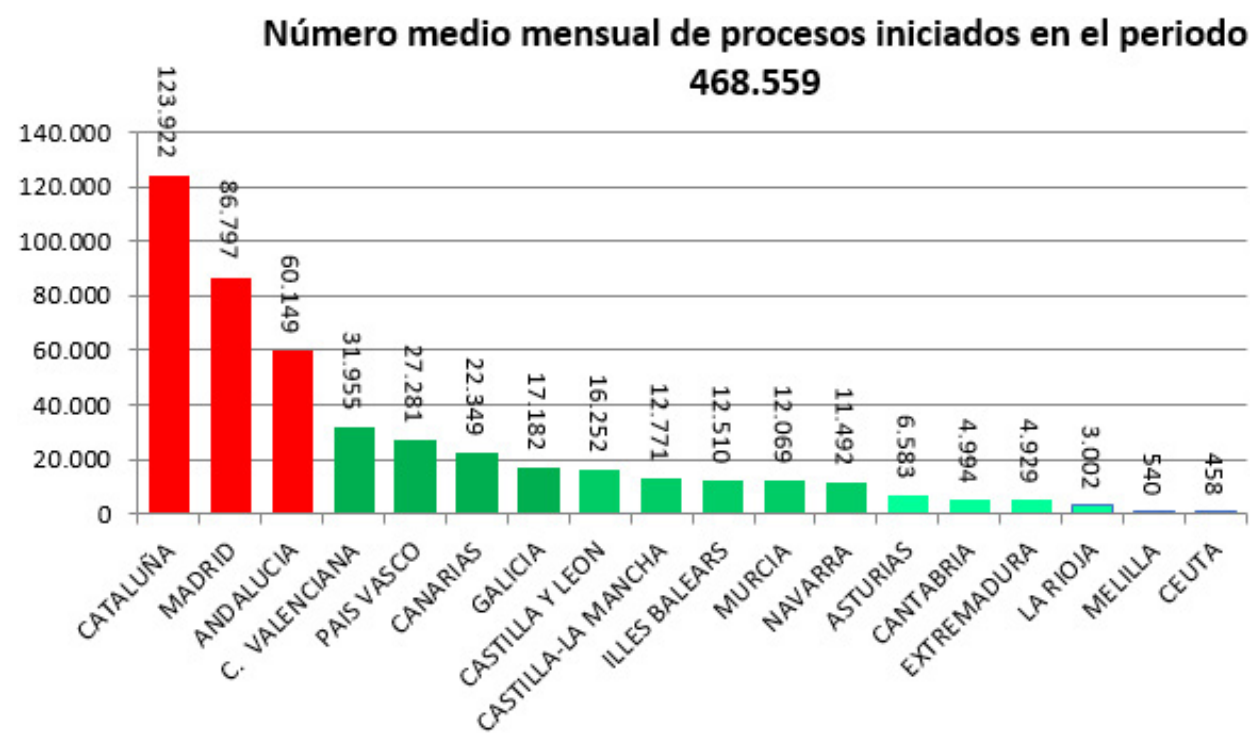


En cuanto al número de procesos en vigor al final del periodo Cataluña tiene 105.633, Andalucía tiene 85.590, Madrid tiene 81.877, (Figura 11)

Figura 12. Número de procesos en vigor al final del periodo

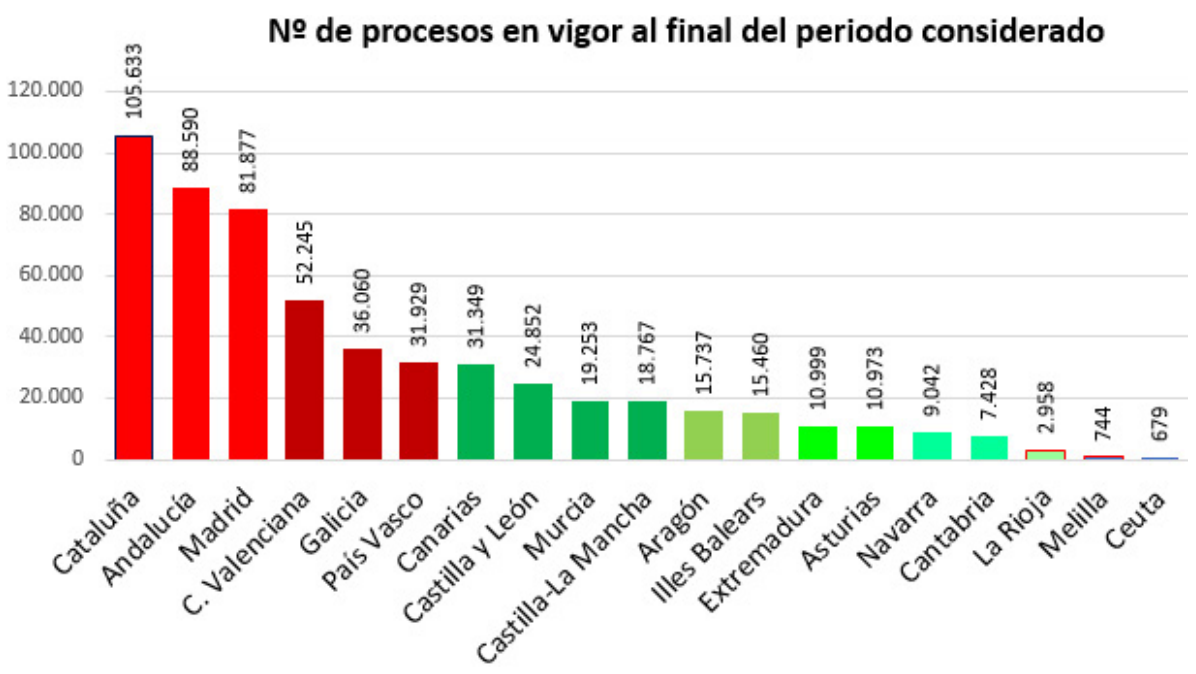

En cuanto a trabajadores protegidos de los 15.649.378, Cataluña tiene 3.051.738, Madrid tiene 2.940.857, Andalucía tiene 2.775.428, la C. Valenciana tiene 1.658.249; estas 4 comunidades copan el $61,23 \%$ de los trabajadores protegidos; Cataluña, Madrid y Andalucía el 51,49\%. (Figura 12).

Figura 13. Número de trabajadores protegidos

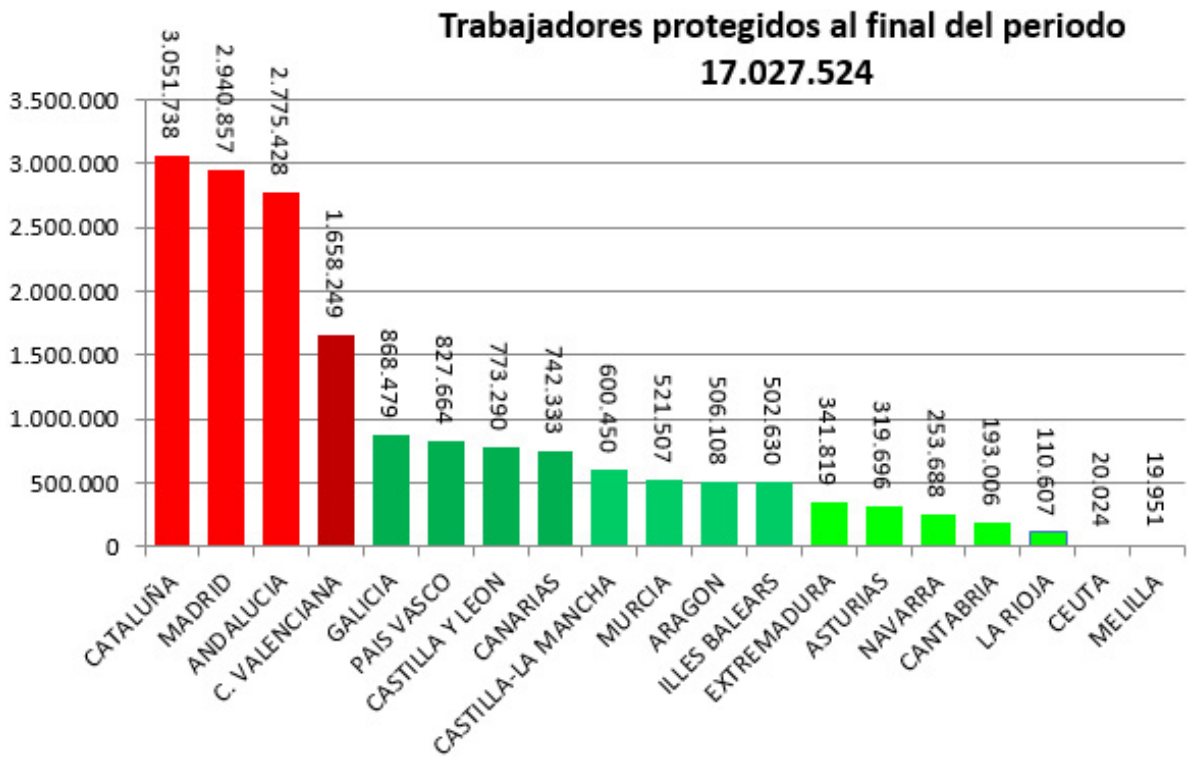

La prevalencia debe ser abordada de forma conjunta con medidas sanitarias que procuren la atención correcta, en tiempo y forma, con cuidado especial a las "factores psicosociales", las banderas amarillas" en el seguimiento de la IT, y preparando un buen retorno promoviendo organizaciones saludables $^{9}$ y mayor comunicación entre el ámbito sanitario, el gestor y el laboral.

\section{3.b. Variabilidad territorial de la Incapacidad Permanente (IP)}

La incapacidad permanente contributiva es la situación del trabajador que, después de haber estado sometido al tratamiento prescrito, presenta reducciones anatómicas o 
funcionales graves, susceptibles de determinación objetiva y previsiblemente definitivas, que disminuyan o anulen su capacidad laboral. No obstará a tal calificación la posibilidad de recuperación de la capacidad laboral del incapacitado, si dicha posibilidad se estima médicamente como incierta o a largo plazo.

La incapacidad permanente es el peor resultado en salud laboral, el indicador de no retorno laboral que mejor expresa la pérdida de capital humano y cuestiona el fracaso en prevención. Y también es un indicador de resultado sanitario, pues un proceso además de otros parámetros a tener en cuenta como indicadores de salud, también este es válido como negativo resultado en salud.

Los datos de IP referidos a 1 de septiembre 2019, han sido extraídos en parte del portal informático de la Seguridad Social, en su aplicación estadística página web, y luego analizados y elaborados para el presente estudio, así como comparados con datos del INE.

Hemos relacionado número de pensiones en cada comunidad autónoma con número de afiliados en esa comunidad, para establecer una proporcionalidad de referencia, más allá del ranking por el exclusivo número de pensiones por comunidades autónomas que como es lógico guarda relación con población trabajadora; pero es al poner las incapacidades por grados en cada comunidad autónoma por cada mil afiliados cuando esta relación refleja las diferencias significativas por territorios y merece un análisis pormenorizado que reflejaran la causa.

El primer análisis lo haremos sobre el cómputo global de la incapacidad permanente, es decir de todas las incapacidades en cualquiera de sus grados, por comunidad autónoma.

Figura 14. Incapacidad Permanente por mil trabajadores afiliados

Tasa Incapacidad Permanente \%o afiliados

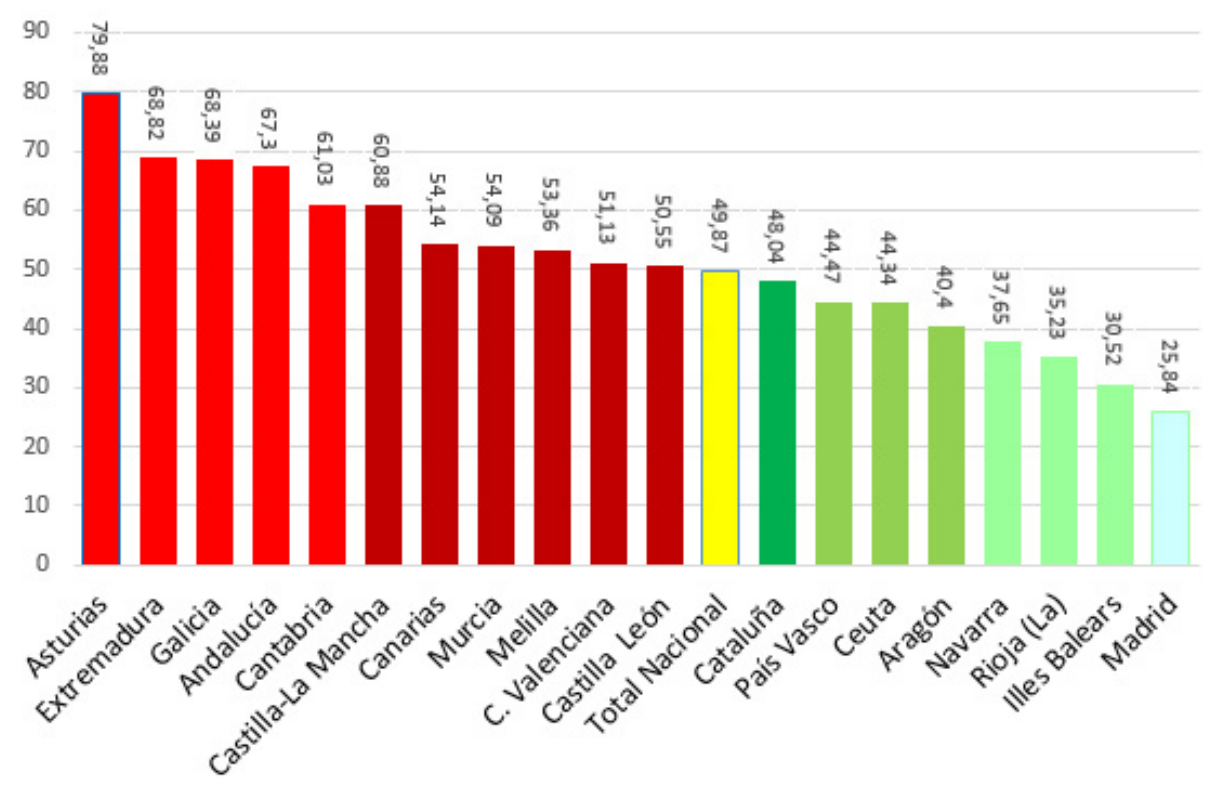

Como vemos la variabilidad de presentación de la incapacidad permanente por comunidades autónomas es muy significativa, pareciera desprenderse de los datos que a continuación se señalaran para cada supuesto, que residir en determinadas comunidades autónomas está en relación directa con mayor porcentaje de incapacitados permanentes, y por el contrario vivir en determinados territorios de España supusiera un mayor nivel de capacidad laboral saludable (menor número de incapacitados). Figura 14.

Así grosso modo, aunque luego especificaremos, destaca como comunidad autónoma extraordinariamente "saludable laboral" por su significativo menor porcentaje de incapacidades permanentes por mil trabajadores Madrid con 25,84, 
junto a Baleares 30,52 La Rioja 35,23 Navarra 37,65 Aragón 40,4 y son las comunidades "menos saludables laboralmente" con mayor porcentaje de incapacidades permanentes, Asturias 79,88 Extremadura 68,82, Galicia 68,39, Andalucía 67,3, y Cantabria 61,03; con una medida Nacional de 49,87.

Figura 15. Tasas de Incapacidad y Desempleo por CCAA

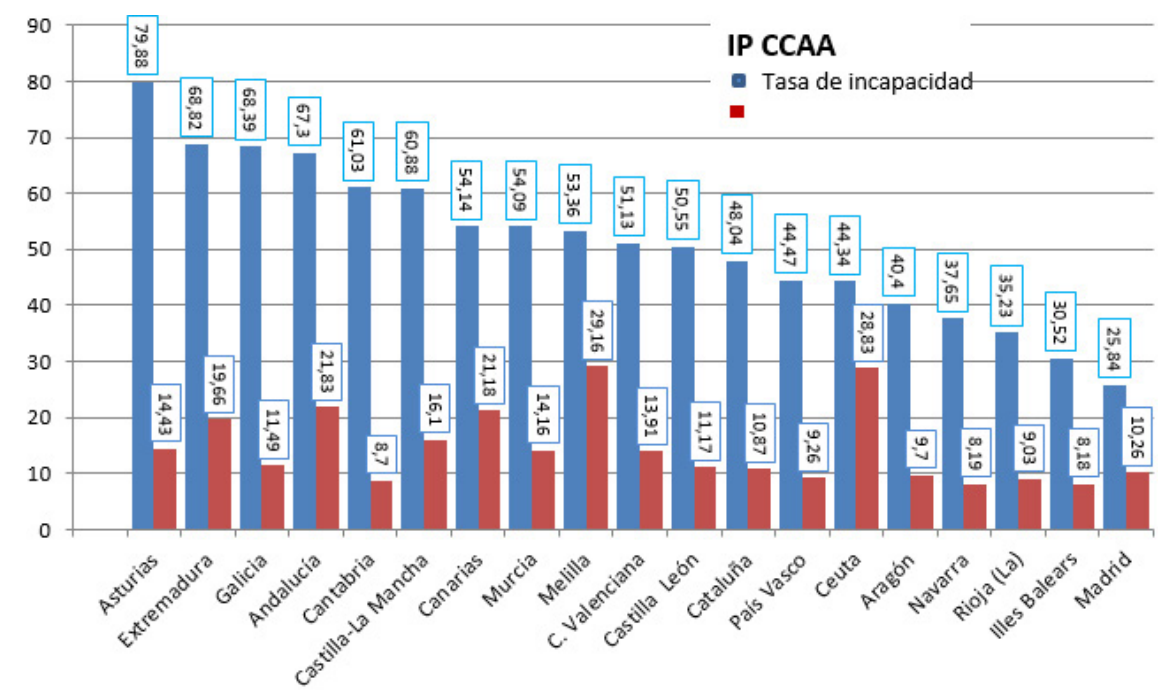

La relación entre comunidades con mayor tasa de desempleo no se corresponde linealmente con las de mayor o menor número de incapacidades permanentes por mil trabajadores afiliados. Figura 15. Pero sí, si hacemos una traslación de ambas tasas desempleo e incapacidad a nivelación de 1 a 10 , convirtiendo estos valores en "factor de desempleo" y "factor de incapacidad" finalmente la suma de estos nos ofrece una imagen gráfica de comunidades con trabajadores incapacitados permanentes y con trabajadores desempleados, lo que nos da una referencia de comunidades con más trabajadores “dependientes económicamente de una prestación”, dando también una traslación visual similar de autonomías "ricas" que tienen menos incapacitados y menos desempleo; así como comunidades con muy alto nivel de paro que tienen así mismo alto nivel de incapacidad permanente (Andalucía y Extremadura).

Figura 16. Factor Incapacidad y Factor Desempleo

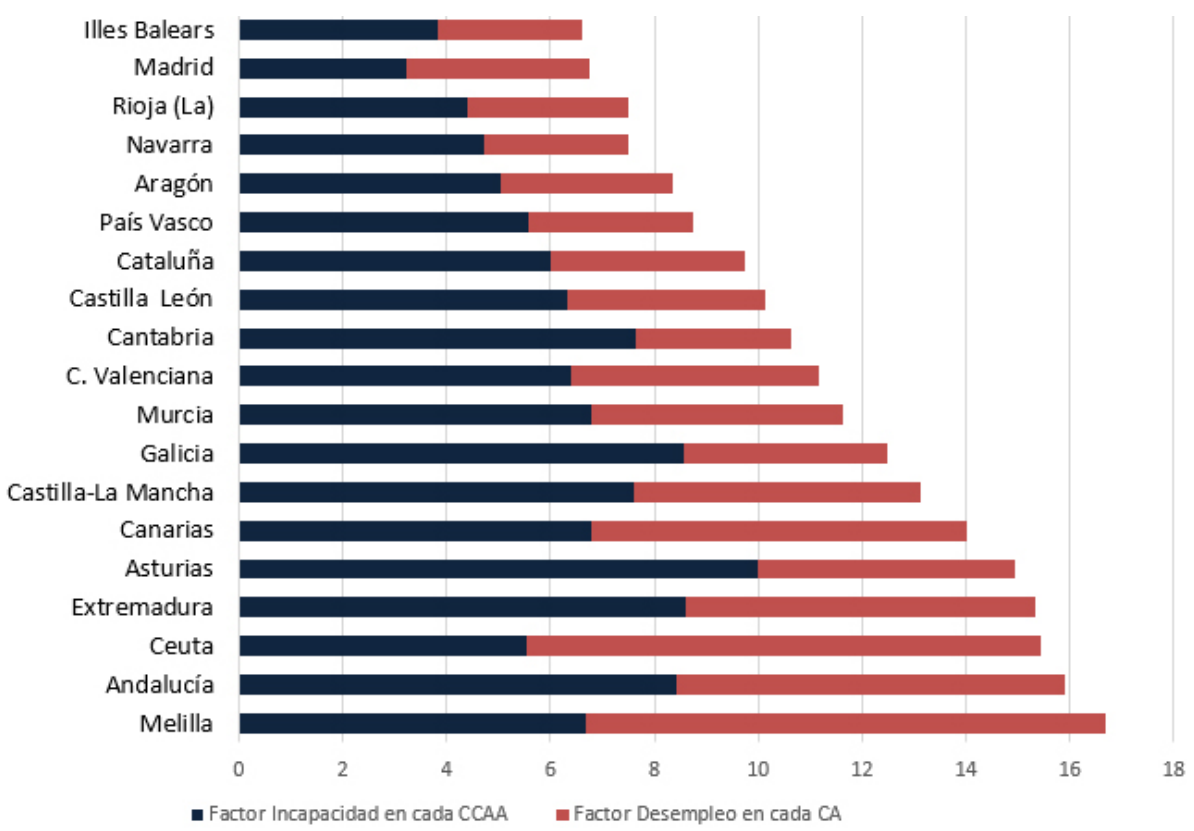


A continuación, reflejaremos los datos de la Gran Invalidez, La Incapacidad Permanente Absoluta y la Incapacidad Permanente Total.

Anotar que las situaciones de gran invalidez son las de incapacitados que precisan de ayuda para actividades de la vida diaria, la incapacidad absoluta se entiende quien está incapacitado para todo trabajo y la total la de quien está incapacitado para el trabajo que venía desempeñando, siendo la incapacidad total cualificada (75\%) la que en este caso de estar impedido para su profesión habitual tiene más de 55 años y se encuentra sin trabajo.

A los efectos de población "no activa laboral" contemplar lo que representa para el sistema productivo y de recaudación las incapacidades absolutas y las totales cualificadas, al considerar son trabajadores que no trabajarán (en principio) y son perceptores de prestaciones compensatorias.

A continuación, analizaremos los datos sobre cada uno de los grados de la incapacidad permanente.

\section{La Gran invalidez}

Se entenderá por gran invalidez la situación del trabajador afecto de incapacidad permanente y que, por consecuencia de pérdidas anatómicas o funcionales, necesite la asistencia de otra persona para los actos más esenciales de la vida, tales como vestirse, desplazarse, comer o análogos.

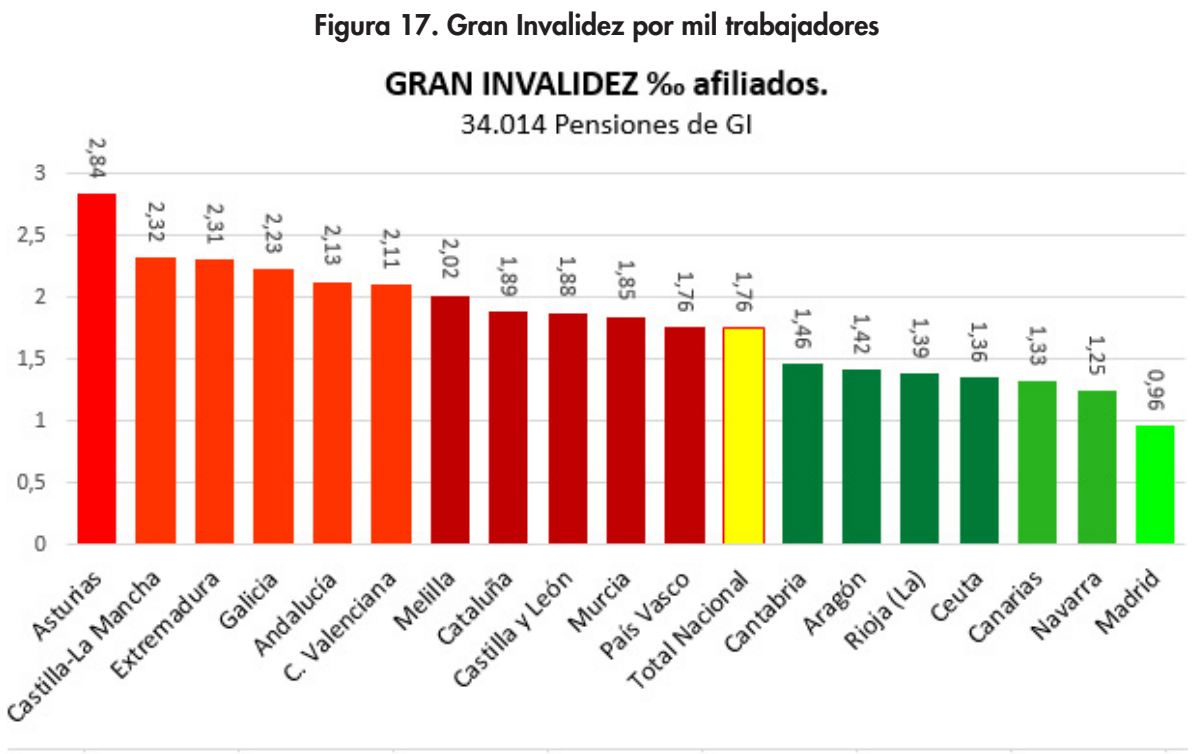

Cataluña tiene el doble de grandes inválidos que Madrid con un número de afiliados parejo.

Si establecemos una ratio por mil afiliados destacan por tener mayor porcentaje de Gran Invalidez Asturias con 2,84\%o, Castilla La Mancha con 2,32\%o, Extremadura con 2,31\%o. Galicia con 2,23\%o, Andalucía con 2,13\% y C. Valenciana con 2,11\%o.

Sin embargo, La Rioja con 1,39\%o, Ceuta con 1,36\%, Canarias con 1,33\%o, Navarra con 1,25\% , y Madrid con $0,96 \%$, son las comunidades autónomas con menor proporción de Grandes Inválidos por mil afiliados. El cómputo del Total Nacional de gran invalidez preexiste del 1,76\%o. (Figura 17).

No olvidemos que la consideración de Gran Invalidez conlleva la objetivación de la necesidad de $3^{\mathrm{a}}$ persona para la realización de las actividades básicas de la vida diaria, derivada de las limitaciones funcionales incapacitantes definitivas. 
Esta diferencia territorial es difícil guarde relación con lo laboral, y más parece pueda ser debida a diferentes criterios del órgano valorador EVI, en Cataluña CEI o las diferencias de soporte social, desde luego no parece tampoco, guardan relación con la variable salud o sanitaria, pues no hay significación con procesos de salud ni de lesiones, ni por supuesto con deficiencias sanitarias que así determinen esta situación de gran dependencia.

\section{Incapacidad Absoluta}

Se entenderá por incapacidad permanente absoluta para todo trabajo la que inhabilite por completo al trabajador para toda profesión u oficio.

Figura 18. Incapacidad Permanente Absoluta por mil trabajadores

\section{Tasa IPA \%o afiliados}

Total Incapacitados Absolutos 341.398

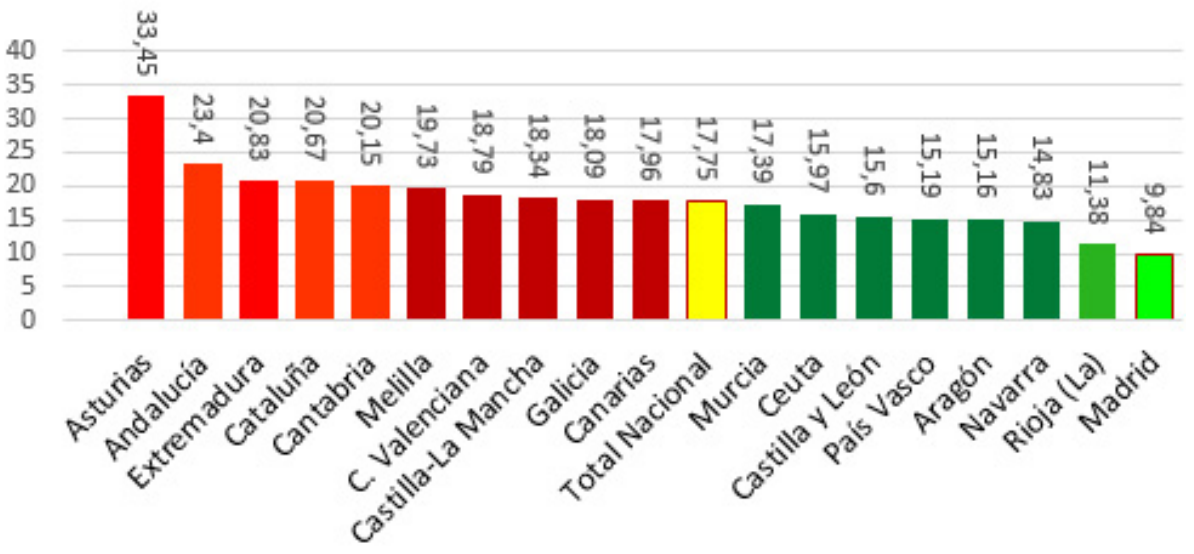

Cataluña tiene más del doble de Incapacitados Absolutos que Madrid con un número de afiliados parejo.

Si establecemos un ratio por mil afiliados destacan por tener mayor porcentaje de Incapacitados Absolutos destacan Asturias con 33,45\%, Andalucía con 23,40\%, Extremadura con 20,83\%o, Cataluña con 20,67\%o, y Cantabria con 20,15\%o.

Sin embargo, País Vasco con 15,19\%o, Aragón con 15,16\%, Navarra con 14,83\%o, La Rioja con 11,38\%o, y Madrid con 9,84\% son las comunidades autónomas con menor proporción de Incapacitados Absolutos. El cómputo del Total Nacional es de 17,75\%.

\section{Incapacidad Permanente Total}

Se entenderá por incapacidad permanente total para la profesión habitual la que inhabilite al trabajador para la realización de todas o de las fundamentales tareas de dicha profesión, siempre que pueda dedicarse a otra distinta.

Incapacidad Permanente Total. (Figura 19) Si establecemos un ratio por mil afiliados destacan por tener mayor porcentaje de Incapacitados Totales Galicia con 28,80\%, Extremadura con 24,49\%o, Asturias con 23,50\%, Castilla La Mancha con 23,43\%o, y Andalucía con 22,53\%.

Sin embargo, Cataluña con 13,28\%o, País Vasco con 12,94\%, Navarra con $12,56 \%$, La Rioja con $12,46 \%$ y Madrid con $8,54 \%$ son las comunidades autónomas con menor proporción de Incapacitados Totales. El cómputo porcentual del total de incapacidades totales es del 16,57\%o. 
Figura 19. Incapacidad Permanente Total por mil trabajadores

Tasa IPT \%o afiliados

Total Incapacitados Totales 310.814

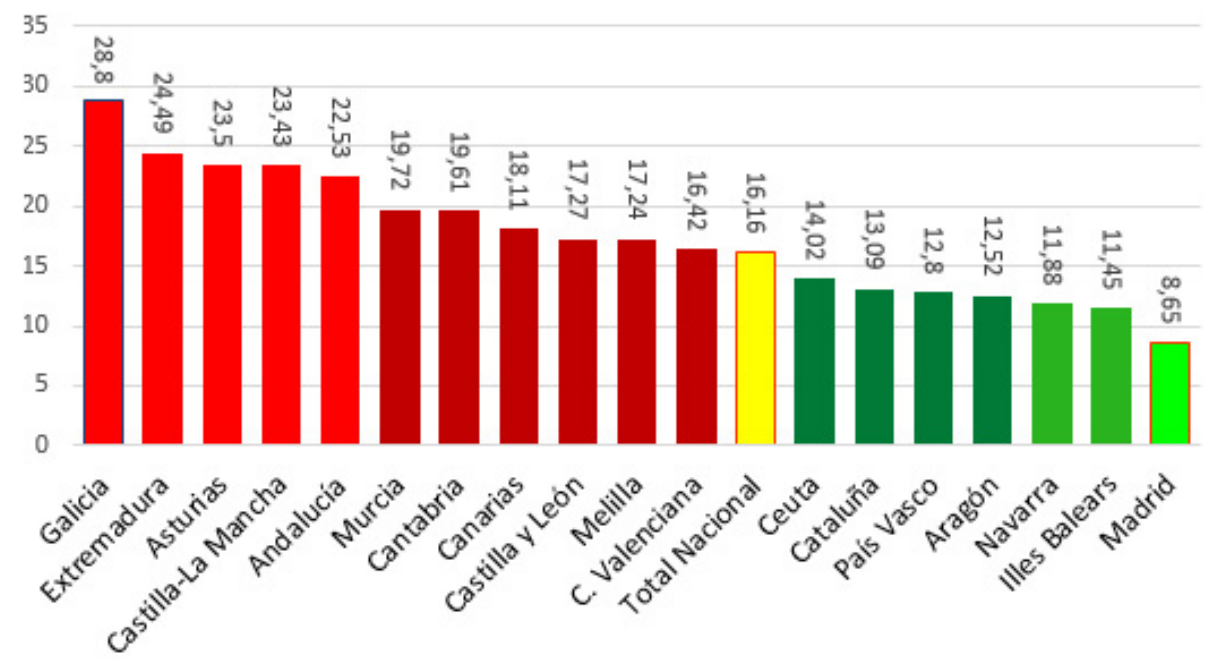

\section{Incapacidad Permanente Total Cualificada}

La incapacidad permanente total cualificada es un aumento de la cuantía de la pensión por incapacidad total en un 20\%, siempre que se cumplan 2 requisitos: Tener más de 55 años y no estar trabajando en la actualidad.

Figura 20. Incapacidad Permanente Total Cualificada por mil trabajadores

\section{Tasa IPT C \%o afiliados}

Total IPT cualificada 265.035

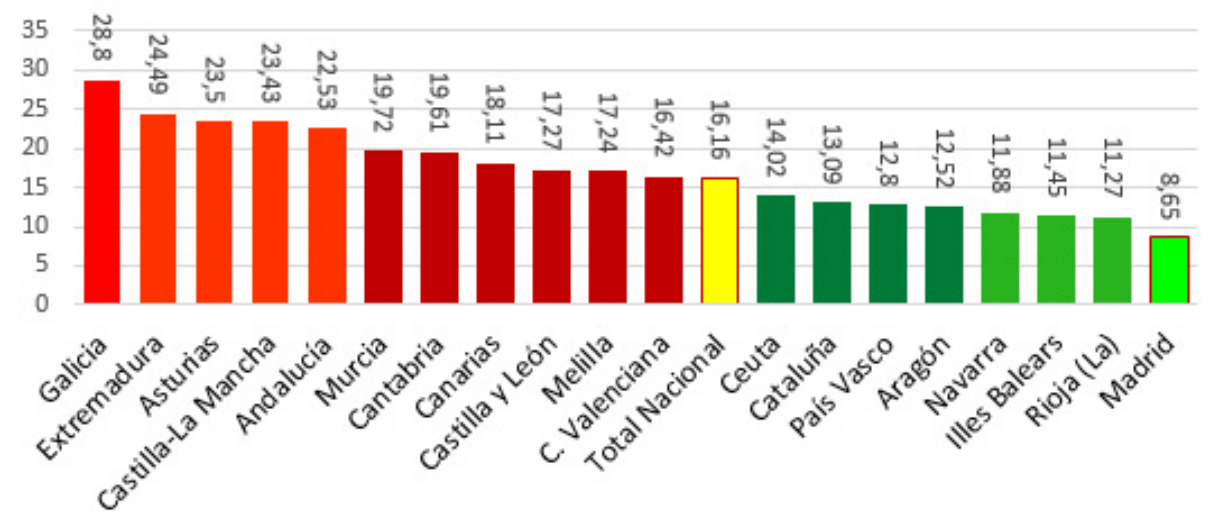

Incapacitados totales mayores de 55 años y que no trabajen.

Las comunidades autónomas con mayor porcentaje por mil afiliados de Incapacitados Totales Cualificadas, trabajadores con incapacidad total mayores de 55 años son Galicia con 24,61\%o, Asturias con 20,63\%o, Extremadura con 19,97\%o, Cantabria con 19,49\%o, y Andalucía con 19,19\%.

Cataluña con 13,90\%o, País Vasco con 12,80\%o, Aragón con 12,52\%o, Navarra con 11,85\%o, Illes Balears con 11,45\%o, La Rioja con 11,17\%o, y Madrid con 8,65\%o son las comunidades autónomas con menor proporción de Incapacitados Totales Cualificadas. El cómputo porcentual del total de incapacidades totales en mayores de 55 años es del 13,82\%o (Figura 20). 


\section{Consideraciones globales sobre los datos sobre la variabilidad territorial de la incapacidad permanente}

Las seis comunidades autónomas con mayor porcentaje total de Incapacitados, es decir trabajadores con incapacidad de cualquier grado, son Asturias con $79,88 \%$, Extremadura con $68,82 \%$, Galicia con $68,39 \%$, Andalucía con $67,30 \%$. Cantabria con 61,03\% y Castilla La Mancha 60,88. Estas seis comunidades autónomas con 391.338 incapacitados tienen el 40,81 de los incapacitados, sobre 5.809.538 trabajadores

Sin embargo Aragón con 40,40\%o, Navarra con 37,65\%, La Rioja con 35,26\%, Illes Balears con $30,52 \%$, y Madrid con $25,84 \%$ o son las comunidades autónomas con menor proporción de Incapacitados, entre las cinco alcanzan 35.442 incapacitados el 14,47\% de los incapacitados con 4.766 .647 trabajadores afiliados el $82 \%$ de afiliados, de las 6 comunidades autónomas donde hay mayor tasa de incapacidad.

Es significativo que Andalucía con 3.091.414 afiliados (trabajadores) y 208.067 incapacitados, (tasa de IP por mil trabajados de 67,30) y Cataluña con 3.437 .158 trabajadores y 165.142 incapacitados (tasa de IP 48,04\%o afiliados) tengan más del doble de incapacitados que Madrid con 83.057 incapacitados y 3.213.065 afiliados (tasa de IP $\mathbf{2 5 , 8 4 \%}$ afiliados). Si trasladamos la comparativa por tasa de incapacidad por cada mil afiliados Asturias con $79,88 \%$ triplica a Madrid con $25,84 \%$ y tiene una tasa IP \%o del 1,60 más que la tasa nacional, Extremadura y Galicia tienen una tasa IP \%o del 1,37 más que la tasa nacional, Andalucía del 1,34 más que la tasa nacional. (Figura 14)

Anotar que los incapacitados permanentes se diluyen en su seguimiento al pasar a la edad de jubilación. Por lo que su impacto en cuanto a salud laboral se esfuma.

Se puede concluir que la incapacidad permanente guarda relación con el "código postal" o en qué la incapacidad responde a la variabilidad de la comunidad autónoma se viva o que hay comunidades autónomas más o menos saludables laboralmente.

La incapacidad permanente es referente de la pérdida de capital humano, reflejo de una mala condición de salud laboral, y analizada junto a proceso incapacitante, actividad y ocupación del incapacitado la expresión de indicador de salud laboral, así como indicador de salud organizacional ${ }^{9}$, y debe llevar a desarrollar planes estratégicos para su prevención, políticas preventivas de riesgos laborales y de promoción de la salud, e implantar políticas que favorezcan el retorno laboral'5.

\section{CONCLUSIONES}

La variabilidad territorial está presente en la incapacidad laboral tanto temporal como permanente, hasta el punto que podemos asignar valor de salud laboral por territorios (comunidades autónomas). La variabilidad territorial refleja el hecho de que la incapacidad se presenta de forma distinta según la comunidad autónoma donde se reside. Lo que convierte al ámbito geográfico en un condicionante sobre la salud.

La incapacidad laboral es un indicador de salud pública (nos mide el enfermar o el deterioro de la salud hasta el extremo de lo incapacitante), y en cuanto a la relación de la incapacidad con el trabajo es un claro indicador de salud laboral. La incapacidad laboral es el indicador de salud laboral, que mejor refleja su pérdida. La incapacidad laboral con carácter permanente manifiesta el indicador de retorno laboral y es muy útil de cara a valorar el impacto laboral de un proceso.

A la variabilidad territorial de este indicador de salud laboral debiera añadirse la relación por procesos, edad, sexo, actividad y ocupación, de los trabajadores incapacitados lo que ayudaría a conocer mejor las causas y consecuencias de la incapacidad e instaurar medidas preventivas para evitar su aparición, procurar su pronta recuperación e impedir que la vuelta al trabajo sea no saludable. A este estudio que 
presentamos sigue faltando algo que se viene reclamando y es la necesidad urgente de confección del "Mapa de Incapacidad Laboral" que reportaría datos sobre la a quién, cómo y de qué manera afecta la incapacidad laboral, lo que sería una herramienta en prevención extraordinaria ${ }^{10}$.

La variabilidad territorial de la incapacidad laboral y los factores que la condicionan puede ser de utilidad en el análisis preventivo, como prevención primaria para evitar que la incapacidad se produzca, cuando aparezca para evitar que se prologue y procurar la pronta recuperación de quién padece una incapacidad laboral (prevención secundaria) y actuar como prevención terciaria procurando la reintegración al trabajo con un retorno saludable, sin que el trabajo perjudique su salud o sea causa de recaída, que además sea un retorno duradero y sea eficiente es decir puede desempeñar su trabajo adecuadamente ${ }^{11}$.

La variabilidad territorial de la incapacidad laboral debe contemplarse desde la perspectiva del enfermar de la población laboral, es decir, con criterios de salud laboral, más allá de su consideración economicista o peor aun victimizando al trabajador que la padece. Pues en ocasiones esta variabilidad territorial parece sólo despierta el interés por el recorte de las desviaciones, y finalmente el recorte en el coste de la prestación.

Es preciso analizar el porqué de esta variabilidad territorial, la influencia de los determinantes laborales (edad, actividad, ocupación, riesgos, tipo de contrato, jornada, organización empresarial), los determinantes sociales (factores psicosociales) y los determinantes sanitarios (salud pública, prestación atencional sanitaria en tiempo y forma).

Asumir principalmente la incapacidad laboral como un indicador de salud laboral y la variabilidad en su presentación territorial como un determinante a analizar,

\section{REFERENCIAS BIBLIOGRÁFICAS}

1. Vicente Pardo, José Manuel. (2018). La gestión de la incapacidad laboral algo más que una cuestión económica. Medicina y Seguridad del Trabajo, 64(251), 131-160. Disponible en: http://scielo.isciii.es/ scielo.php?script=sci_arttext\&pid=S0465-546X2018000200131\&lng=es\&tlng=es.

2. Vicente Pardo, José Manuel, \& López-Guillén García, Araceli. (2018). Los factores psicosociales como predictores pronósticos de difícil retorno laboral tras incapacidad. Medicina y Seguridad del Trabajo, 64(250), 50-74. Disponible en: http://scielo.isciii.es/scielo.php?script=sci_arttext\&pid=S0465546X2018000100050\&lng=es\&tlng=es.

3. Vicente Pardo, José Manuel. Incapacidad laboral, riesgo moral y riesgo laboral. Disponible en: http:// prevencionar.com/2018/05/08/incapacidad-laboral-riesgo-moral-y-riesgo-laboral/

4. Vicente Pardo, José Manuel. (2016). Reflexión sobre los problemas a la reincorporación laboral tras incapacidades médicas largas. Revista Medicina y Seguridad del Trabajo, 62(242), 49-65. Disponible en: http://scielo.isciii.es/scielo.php?script=sci_arttext\&pid=S0465-546X2016000100006\&lng=es

5. López-Guillén García, Araceli, \& Vicente Pardo, José Manuel. (2018). Necesidad de políticas de retorno al trabajo tras incapacidad laboral prolongada, en materia de seguridad social. Medicina y Seguridad del Trabajo, 64(253), 379-401. Disponible en: http://scielo.isciii.es/scielo.php?script=sci_arttext\&pid=S0465546X2018000400379\&lng=es\&tlng=es.

6. Informe 2019 Los Servicios Sanitarios de las CCAA FADSP. Disponible en: http://www.fadsp.org.

7. La sanidad española en cifras 2018. Fundación Gaspar Casal. Disponible en: http://fundaciongasparcasal. org/publicaciones/Sanidad-espanola-en-cifras-2018.pdf

8. López-Guillén García, Araceli, \& Vicente Pardo 2018“Banderas Amarillas" en el alargamiento de la incapacidad laboral 2018. Disponible en: https://prevencionar.com/2018/08/26/banderas-amarillas-enel-alargamiento-de-la-incapacidad-laboral/

9. Villaplana García, María Dolores. Absentismo e incapacidad laboral: Promover organizaciones saludables como garantía de excelencia y efectividad organizativa. Oviedo: Consejo Económico y Social del Principado de Asturias; 2015. Disponible en: https://ria.asturias.es/RIA/handle/123456789/5385 
10. López-Guillén García, Araceli, \& Vicente Pardo El Mapa de Incapacidad Laboral como herramienta en la gestión y la prevención. Disponible en: https://prevencionar.com/2017/09/24/mapa-incapacidad-unanecesidad-urgente/

11. López-Guillén García, Araceli, \& Vicente Pardo Políticas para un retorno al trabajo saludable tras incapacidad laboral prolongada. Disponible en: https://prevencionar.com/2019/06/06/politicas-para-unretorno-al-trabajo-saludable-tras-incapacidad-laboral-prolongada/

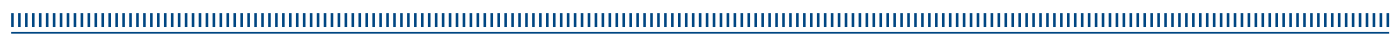

